\title{
(1)
}

UNIVERSIDAD PERUANA DE CIENCIAS APLICADAS

FACULTAD DE PSICOLOGIA

CARRERA DE PSICOLOGIA

\section{Optimismo Disposicional y Afrontamiento en Padres \\ de Niños con Autismo}

\author{
TESIS \\ Para optar el Titulo Profesional en Psicología
}

AUTORES

Katitza Viviana Miskulin Gilardi (0000-0003-0520-3424)

ASESOR DE TESIS

Karen Macavilca Milera (0000-0001-6198-6318) 


\section{RESUMEN}

En la presente investigación se tuvo como objetivo estudiar la relación entre el optimismo disposicional y el afrontamiento activo y evitativo en un grupo de 94 padres de niños entre 3 a 13 años de edad diagnosticados con autismo que residen enla ciudad de Lima. Para ello se aplicó el Cuestionario de Orientación Vital - Revisado (LOT-R; Grimaldo, 2004) orientado a medir el Optimismo Disposicional y la Escala de Estrategias de Afrontamiento Modificada (EEC-M; Londoño, Henao, Puerta, Posada, Arango \& Aguirre - Acevedo, 2006) para medir el Afrontamiento que los participantes utilizaban. Los resultados mostraron una relación significativa y positiva entre las variables mencionadas; indicando que los padres que perciben el futuro de manera positiva podrían sobrellevar experiencias que incluyen la convivencia con la condición de su hijo de manera más adaptativa.Además, los resultados son similares a los obtenidos en estudios anteriores realizados en la población estudiada. Se exponen también, las limitaciones encontradas en el transcurso del estudio y sugerencias diversas que se pueden tener en cuenta para posteriores investigaciones.

Palabras clave: Autismo, Optimismo, Afrontamiento, Padres, Niños 


\section{ABSTRACT}

This research aimed to describe the relationship between dispositional optimism and active and avoidant coping in a sample of 94 parents of children between 3 and 13 years old diagnosed with autism of Lima city. Life Orientation Test - Revised (LOT-R, Grimaldo, 2004) was applied to measure the Dispositional Optimism, and the Modified Coping Strategies Scale (EEC-M, Londoño, Henao, Puerta, Posada, Arango \& Aguirre Acevedo, 2006) to measure the Coping that the participants used. Among the results, it was found a significant and positive relationship between the mentioned variables; showing that parents who perceive the future in a positive way could cope in a more adaptive way with experiences that include coexistence with their child's condition. In addition, the results are similar to those obtained in previous researchs with the same sample characteristics. Also are exposed the limitations found during the study and suggestions that may be taken for further research.

Keywords: Autism, Optimism, Coping, Parents, Children 


\section{TABLA DE CONTENIDO}

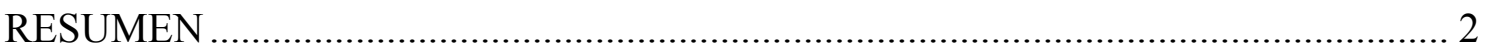

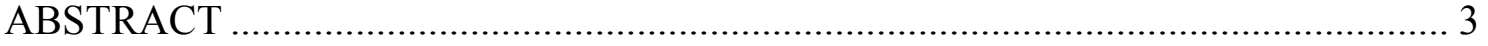

Capítulo 1. Optimismo Disposicional y Afrontamiento en padres de niños con Autismo6

1.1. Autismo 7

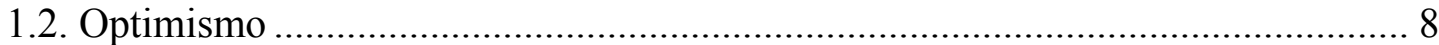

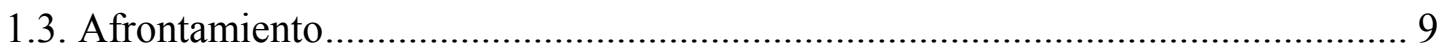

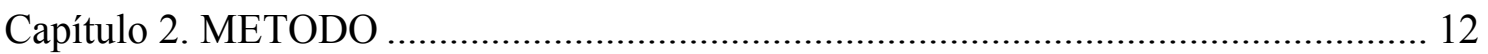

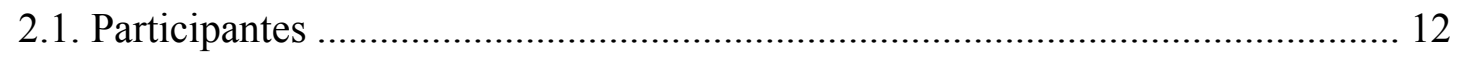

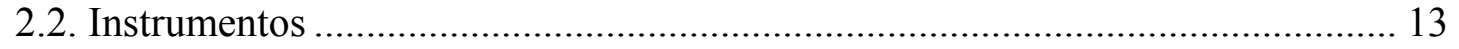

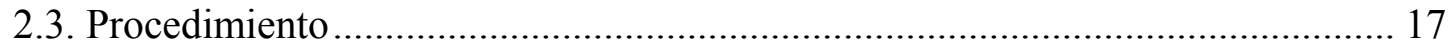

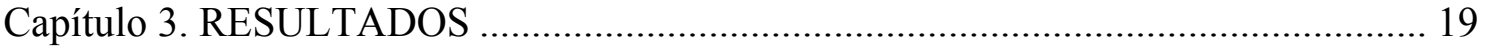

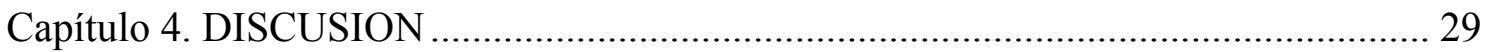

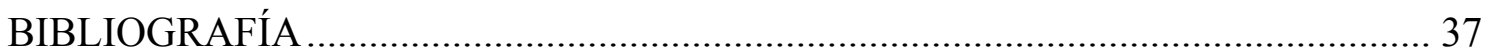

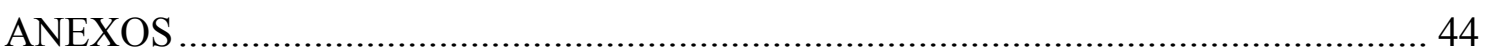




\section{INDICE DE TABLAS}

Tabla 1. Propiedades psicométricas de esta prueba validadas en el Perú....................... 16

Tabla 2. Afrontamiento Activo y Evitativo con los cuatro factores mencionados......... 17

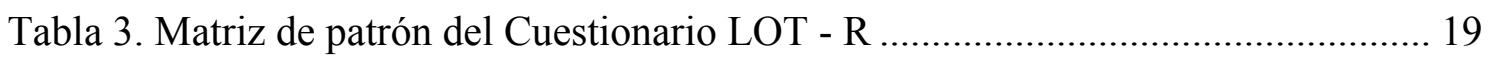

Tabla 4. Estadístico total elemento del cuestionario LOT - R..................................... 20

Tabla 5. Cargas factoriales de los ítems de la nueva estructura de la prueba EEC-M ... 21

Tabla 6. Cargas factoriales de los ítems de la prueba EEC-M ...................................... 22

Tabla 7. Correlación elemento total - corregida del componente Afrontamiento Activo

Tabla 8. Correlación elemento total - corregida del componente Afrontamiento Evitativo

Tabla 9. Estadísticos descriptivos para el componente Optimismo Disposicional, Afrontamiento Activo y Afrontamiento Evitativo 25

Tabla 10. Prueba de Normalidad de la Ocupación Actual con las variables psicológicas 


\section{Capítulo 1. Optimismo Disposicional y}

\section{Afrontamiento en padres de niños con Autismo}

Los padres cumplen el papel principal en el desarrollo biológico, psicológico, social y moral adecuado de los miembros de la familia (Benites, 2010); son los responsables de guiar las conductas de los hijos de acuerdo a su personalidad y además enfatizar la apropiada interacción con el entorno. La tarea de ser padre o madre manifiesta la responsabilidad de velar por el bienestar integral del hijo, desde el ámbito físico hasta el emocional(Ramírez, 2005).

Cuando se recibe el diagnóstico de autismo de uno de los hijos, los padres atraviesan un proceso de duelo similar al planteado por Kübler Ross, pues deben renunciar a las expectativas de tener un hijo sin ninguna dificultad; inicialmente atraviesan por una etapa de negación hasta lograr la aceptación del acontecimiento(Martínez, M. y Bilbao, M., 2008)

La principal sensación percibida y estudiada en los padres de niños con autismo es el estrés. Desde el ámbito de pareja, el estréscombina sentimientos de impotencia y preocupación con otros de culpabilidad que limitan la iniciativa de acudir a entornos de soporte tanto sociales como profesionales(Mendoza, 2014). Se ha comprobado que los encargados de velar por las personas con autismo manifiestan mayores dolores corporales (somatización), menor energía, funcionamiento social y emocional en comparación con un grupo control(Khanna, Suresh, Smith, Patrick, Tworek, \& Becker-Cottrill, 2010).

Se han investigado varias respuestas que surgen en los padres luego de confirmar el diagnóstico del menor, desde las menos adaptativas como el miedo, rabia, decepción; y las más adaptativas como amor, ansias de proteger al menor, fuerza para salir adelante frente a la adversidad, etc. Cada una de ellas aparecerá de acuerdo a los recursos personales o limitaciones que posean aquellos miembros de la familia. Por otro lado, en el ámbito de pareja también surgen problemas que se expresan en recriminaciones, reproches o comunicación pobre, que pueden desencadenar posibles separaciones cuando no se logra un trabajo de apoyo entre ambos. Todas estas maneras de convivir con la condición del menor dependerá de la dinámica que se tenga dentro del hogar y del 
equilibrio emocional y social que se construya a partir de las expectativas sobre el avance del hijo(Sánchez \& Velasquez, 2014).

Por esto, se cree que lo que surge con los padres después de diagnosticar autismo en su hijo, no sólo depende del nivel de gravedad de éste, sino que existen y juegan un papel fundamental variables personales, de pareja y del entorno, las cuales conducen el modo de enfrentar la dinámica en relación al autismo, junto a las formas de ver la vida a futuro de cada progenitor(Sánchez \& Velasquez, 2014). Por este motivo, el presente trabajo busca responder a la pregunta si existe relación entre el optimismo de los padres y el afrontamiento que llevarán a cabosobre las situaciones que involucren, además, la condición de autismo en su hijo.

Esta investigación busca aportar nuevos resultados para que las instituciones educativas conozcan sobre la relación que existe entre estas variables psicológicas. Estos nuevos datos podrían ser clave en la ayuda que las institucionesbrindena los progenitores como programas psico - educativos, charlas, grupos de apoyo, etc. Cabe resaltar que la correlación de ambas variables no ha sido estudiada anteriormente, si bien existen investigaciones con variables similares en el Perú respecto a padres de niños con autismo (Mendoza, 2014; Pérez de Velasco, 2017; Falcón, 2017; Arphi, Sánchez\& Vásquez, 2017), aún falta conocer la relación que existe entre éstas en una población con características particulares.Un gran número de investigaciones analizan el estrés, depresión o insatisfacción personal de los padres, mas no de conceptospositivos, de esta manera aportará a una mejor comprensión de percibir la vivencia que llevan los padres de niños con autismo hacia un plano más alentador y con expectativas confortadoras.

\subsection{Autismo}

El autismo es uno de los trastornos generalizados del desarrollo, analizado inicialmente por Breuler en 1919 y años más tarde, en 1943, por Kanner, dando los primeros indicios de lo que sería dicha condición(Giles, 2007)Ésta se caracteriza por una alteración en las habilidades comunicativas, de interacción social, la presencia de conductas estereotipadas enfocadas a una actividad en particular, así como la hiperactividad, pues al ser personas con un gran desarrollo sensorial, el ambiente fomenta que el cuerpo del niño con autismo esté en constante movimiento (Marcelli \& De Ajuriaguerra, 2006). 
En 1990 se investigó con mayor énfasis el autismodebido al aumento significativo del número de niños diagnosticados en aquella época y los servicios asistenciales que surgían a la par(Baio, 2012). Con ello, se ha tenido acceso a datos por medio de la Organización Mundial de la Salud(OMS, 2016), en el que se especifica que 1 de cada 160 niños son diagnosticados con autismo; sin embargo, según el Instituto Nacional de Estadística e Informática (2014) no hay estadísticas específicas en el Perú, ya que las personas diagnosticadas con autismo son consideradas dentro del grupo de personas con discapacidades generales (físicas, mentales, sensoriales, sociales o intelectuales). Se señala que en varones es cuatro veces mayor la presencia de autismo en comparación de las mujeres(Giles, 2007).

\subsection{Optimismo}

Al realizarse el diagnóstico, los padres deben ser capaces de poner en acción recursos psicológicos para poder preservar y proteger su bienestar e integridad personal, como pareja y como padres (Remor, Amorós, \& Carrobles, 2006). El optimismo, entonces, toma lugar definiéndose como aquella disposición estable o tendencia que consiste en tener proyecciones y expectativas positivas capaces de modificar panoramas que predomine el estrés(Morales, y otros, 2011). Es también entendido como un modelo de autorregulación de conducta, debido que al percibir entornos amenazantes las variables positivas aumentan el esfuerzo de cada persona para llegar al objetivo(Morales, y otros, 2011), teniendo claro que estos sucesos se deben a causas externas auno mismo, inconsistentes en el tiempo y específico en ese ámbito particular de la vida.

Segerstrom(Grimaldo, 2004).refieredos estilos de optimismo: disposicional y situacional; el estilo disposicional propone el modo continuo de hacer frente a las sucesos en general, esto hace que se adopte una postura positiva frente a cualquier realidad que se experimente; el estilo situacional, es aquel mecanismo que se hace presente en la vivencia de un evento en particular estresante que no es constante, permitiendo sobrellevarlo de una manera más saludable.

En cuanto a estudios realizados sobre optimismo, en Colombia se realizó uno con una muestra de 617 estudiantes de educación superior, en el que se obtuvo que las mujeres presentaban mayor nivel de optimismo disposicional que los varones. Asimismo, el estudio se expandió hacia personas que residían tanto en la capital de Colombia como en provincias, donde se verificó que aquellas que radicaban en Bogotá presentaban mayor 
grado de optimismo que los que vivían en provincia, lo cual abrió una hipótesis de que podría deberse a las facilidades educativas, sociales y laborales que presenciaban en la capital(Londoño, Hernandez, Alejo, \& Pulido, 2013)

(Vera-Villarroel \& Guerrero , 2014), constataron que las personas optimistas presentan menos estrés, tienen menor disposición a enfermarse y utilizan estilos de afrontamiento centrados en el problema, valorando de forma más positiva situaciones adversas y buscando apoyo social; en comparación con las personas pesimistas, quienes tendían a refugiarse en la negación de la realidad, a rendirse y a no comprometerse con el objetivo trazado. Es importante recalcar que la persona optimista no niega los diferentes contextos problemáticos en los que se encuentra, sino que es capaz de enfrentar la realidad de manera más activa y directa en busca de revertir dicha situación estresante(Salgado, 2009).

En el campo del autismo,(Mendoza, 2014) realizó un estudio en Lima - Perú, donde se encontró que el $54.7 \%$ de los padres de niños con autismo presentaban un nivel de optimismo bajo y sólo un 9\% alcanzó un nivel de optimismo alto. Asimismo, no se reportaron diferencias estadísticamente significativas en relación al optimismo y las variables socio - demográficas como el lugar de procedencia y sexo.

Por último, es pertinente aclarar que no es necesario ubicarse en dos contextos diferentes para experimentar optimismo o pesimismo, refiere (Grimaldo, 2004)que una misma situación puede ser apreciada desde cualquiera de las dos perspectivas y en cuanto a ello se construirán las expectativas hacia el futuro. (Seligman, 2003), contribuyó refiriendo que las personas que tienden a responder de manera optimista son conscientes del panorama negativo frente a ellos; sin embargo, no lo ven como permanente, sino como un evento pasajero y externo.

\subsection{Afrontamiento}

Las personas además de tener una visión específica sobre el futuro también poseen ciertas maneras de enfrentar las situaciones; por ello Lazarus y Folkman(Castaño \& León, 2010)trabajaron el concepto de afrontamiento como el constante cambio entre lo cognitivo y lo conductual para hacer frente a una situación que conlleva a utilizar recursos personales, considerándosele como un factor mediador entre el estrés y la adaptación al nuevo evento. Años más tarde (Cassaretto, Chau, Oblitas, \& Valdez, 2003) lo describen como regulador de los disturbios emocionales enfocados en tolerar las demandas internas 
y externas de un contexto estresante; si este tipo de afrontamiento es adecuado no se presentará malestar, en caso contrario, podría impactar gravemente en la salud.

El estudio más representativo es el realizado por Folkman y Lazarus (Monat, Lazarus, \& Reevy, 2007) en el que divide dos categorías para este concepto: El afrontamiento centrado en el problema y el afrontamiento centrado en las emociones. El primero de ellos se enfoca en intervenir la situación estresante por medio de estrategias activas y directas como realizar un plan, hablar con personas que tengan conocimiento del problema y aquello que demuestre proactividad del sujeto; por el contrario, el afrontamiento centrado en las emociones se guía a partir del manejo de estas emociones mientras se vive la situación de estrés, las cuales pueden ejemplificarse en técnicas de meditación, tomar distancia del contexto o el consumo de sustancias, para evitar enfrentar directamente la situación angustiante.

Según el estudio de(Dabrowska \& Pisula, 2010), el afrontamiento orientado a la emoción está relacionado al estrés parental de los padres de niños con autismo y orientado al problema en relación al estrés de los padres de niños con funcionamiento típico. En otro estudio se pudo observar que la severidad de los síntomas en los niños con autismo predispone diferencias entre el afrontamiento de los padres, en donde a mayor severidad del caso el afrontamiento estará más enfocado a la emoción, mientras que a menor severidad se orientará al problema (Lyons, Leon, Roecker, Phelps, \& Dunleavy, 2010).

Estas categorías se ordenan en relación a las formas de afrontamiento,explicadas en 1986 por Lazarus y Folkman (Krsemien, Monchietti, \& Urquijo, 2005), las cuales se conocen como Afrontamiento Activo y Afrontamiento Evitativo. El primero de ellos responde a esfuerzos que se realizan directamente con la situación en particular, relacionado a fines exitosos y un mejor manejo de la adaptación; en contraste, el afrontamiento evitativo consiste en negar y no enfrentar de manera directa el evento movilizador. Estas formas de afrontamiento contienen a distintas estrategias que utilizan las personas para determinadas situaciones de su vida; Carver, Scheier yWeintraub (Krsemien, Monchietti, \& Urquijo, 2005)clasificaron ciertas acciones específicas que se realizan en un contexto diferentedentro de cada forma de afrontamiento, por ejemplo: respecto al afrontamiento activo encontramos estrategias como realizar una planificación, buscar apoyo instrumental y/o emocional, etc. Mientras que para el afrontamiento evitativo se agruparon las estrategias de renuncia, negación, autocrítica, etc.

En situaciones problemáticas el afrontamiento de una persona debe ir de la mano con una reevaluación del contexto, de la situación en sí y de la valoración que se le da a 
dicha escena, haciéndose cargo uno mismo de su sentido de realidad, del conocimiento de las circunstancias a las que se enfrentará y de sus capacidades de tolerancia que se pondrán a prueba(Casado, 2002). El afrontamiento busca la manera más sana de adaptar el cuerpo y la mente hacia situaciones variadas (Urzúa \& Jame, 2008).

El afrontamiento hacia algún acontecimiento impactará de manera directa la calidad de vida de la persona; tal como menciona (Frazier, 2000)el afrontamiento activo conduciría a un mejor pronóstico en enfermedades crónicas en comparación al afrontamiento evitativo.Un estudio realizado por (Gantiva, Luna, Dávila, \& Salgado, 2010) con pacientes ansiosos y no ansiosos, muestra que aquellos que experimentan ansiedad crónica puntúan de manera más alta en evitación cognitiva; también se muestran datos importantes sobre el afrontamiento activo llevado por los participantes, centrándose en la solución de problemas y la reevaluación positiva de la situación. Ciertamente estos resultados exponen que las personas que no experimentan con frecuencia ansiedad pueden afrontar las situaciones de manera más activa que los que sí la experimentan.

En referencia al autismo, las estrategias de afrontamiento utilizadas por padres y madres están dirigidas a las de escape - huída del cuidado del menor (evitación), las cuales se correlacionaban con mayores niveles de estrés, depresión y ansiedad que aquellos que utilizaban la reestructuración positiva de la problemática (activo) (Hastings \& Johnson, 2001).Asimismo, las madres tienden a llevar un afrontamiento enfocado al problema en comparación a los padres, esto quiere decir que las madres buscan directamente cómo solucionar o equilibrar la condición del menor, en contraste con los padres, quienes adoptan una postura más pasiva (Hastings, y otros, 2005).

Toda esta información despierta ciertas curiosidades sobre los padres que conviven con la condición de vida de su hijo. Por lo tanto, el presente estudio tiene como objetivo analizar la relación entre el optimismo disposicional y el afrontamiento que los progenitores llevan de acuerdo a las experiencias vividas compartiendo la realidad de tener un hijo diagnosticado con autismo.

Esto se plantea pues, el presentarse y valorarse como una persona optimista refleja una habilidad desarrollada para resolver problemas y una fortaleza psíquica capaz de convertir escenarios negativos en otros emocionantes y positivos; por lo que el afrontamiento en este grupo de personas será más adecuado, en comparación a los que puntúen menos en optimismo, los cuales tenderán a refugiarse en el fracaso, impotencia y depresión(Flores Lozano, 2006). 


\section{Capítulo 2. METODO}

\subsection{Participantes}

La población a la que se dirigió el estudio comprendió padres y madres de niños entre 3 y 13 años de edad diagnosticados con autismo que residían en la ciudad de Lima.

La técnica de muestreo fue de tipo no probabilístico intencional, los participantes voluntariamente accedieron a la aplicación de los cuestionarios. Se seleccionó a los participantes que cumplan con todos los requisitos que requería el investigador(Hernández, Fernández, \& Baptista, 2010).

Dado que por las características de la población sólo se pudo evaluar a 94 participantes, se sugirió que se realice el análisis con el programa $G^{*}$ Power, después de realizado el estudio (post hoc) para determinar cuál fue la potencia. En este caso la potencia fue de .95 , tomando en cuenta un error de .05, según los estudios de Cohen (1988)(Ledesma, Macbeth, \& Cortada, 2008). Esto asegura que la correlación hallada es válida $(\mathrm{r}=.33)$ considerando que el tamaño de la muestra es de 94, tal como se mencionó al inicio.

La muestra estuvo, finalmente, compuestapor 94 padres y madres de niños entre 3 a 13 años de edad diagnosticados con autismo que residen en la ciudad de Lima, dentro de los cuales se ha encontrado que el $76.6 \%$ son mujeres $(\mathrm{N}=72)$ y el $23.4 \%$ varones $(\mathrm{N}$ =22). Las edades oscilan entre 19 y 53 años, con una media de 38.35 (D.E=6.96), teniendo como rango entre 1 a 7 hijos por participante. Uno de ellos tiene estudios primarios (1.1\%), 27 cuentan con estudios secundarios (28.7\%), 22 son técnicos $(23.4 \%)$, 31 tienen estudios universitarios (33\%) y 13 han llevado estudios de post-grado (13.8\%). En cuanto al estado civil 11 son solteros (11.7\%), 72 casados o convivientes $(76.6 \%), 5$ viudos $(5.3 \%)$ y 6 son divorciados (6.4\%). Referente a la ocupación actual, se observa que 52 personas se dedican a las labores del hogar (55.3\%) y 42 trabajan en oficina $(44.7 \%)$. 


\subsection{Instrumentos}

Se utilizó el Cuestionario de Orientación Vital - Revisado (LOT - R) de Scheier y Carver (Chico, 2002; Grimaldo, 2004; Remor et al., 2006; Morales et al., 2011; Oliden, 2013), el cual tiene como objetivo evaluar las expectativas positivas y/o negativas a futuro del participante(Grimaldo, 2004).

La prueba original (LOT) fue realizada por Scheier y Carver en 1985(Oliden, 2013), contaba con doce ítems: ocho relacionados con el constructo optimismo pesimismo y los cuatro restantes como factores de distracción para el participante. Esta versión fue criticada pues el conjunto de ítems establecía dos factores que no se encontraban interrelacionados de manera sólida, además que los ítems no evaluaban expectativas a futuro como lo sustentaba la teoría de la prueba (Grimaldo, 2004). Por lo tanto, años más tarde se realizaron los cambios pertinentes para que dicha prueba sea más consistente en relación al constructo que pretendía medir (Sheier, Carver, \& Bridges, 1994), eliminando dos ítems que no guardaban relación con las condiciones explicadas (Chico, 2002).

Actualmente, el LOT - R cuenta con diez ítems y con cinco opciones de respuestas basadas en una escala de Likert (1 Muy en desacuerdo, 2 Algo en desacuerdo, 3 Indiferente, 4 Algo en acuerdo, 5 Muy de acuerdo). Cuatro de los ítems (ítems 2, 5, 6 y 8) son utilizados para desviar la evidencia de lo que se estudia en el cuestionario, no siendo contabilizados en el análisis; los seis ítems restantes se enfocan en medir la dimensión del optimismo disposicional (como variable unidimensional). Tres de los ítems están redactados en sentido positivo orientados específicamente a optimismo (ítems 1, 4 y 10) y los otros tres restantes en sentido negativo, orientados a pesimismo (ítems $3,7 \mathrm{y}$ 9).(Velasco, Londoño, \& Alejo, 2014)plantean que contar con sólo 6 ítems puede ser una dificultad en términos de estabilidad de los datos, pues puede variaren el tiempo el tipo de creencia que se asocia a ciertos eventos de la vida; asimismo, algunos resultados de investigaciones anteriores han sido inconsistentes en relación a las diferencias culturales que se han encontrado en las poblaciones estudiadas.

La corrección e interpretación se puede llevar a cabo a partir de dos alternativas: recoger resultados independientes de optimismo vs. pesimismo considerándose exclusivamente aquellos ítems que miden cada uno de estos polos o basándose en la variable global de optimismo disposicional, en el que se deberá recoger las puntuaciones de los seis ítems de la prueba y aquellos que están planteados en sentido negativo 
revertirlos puntajes para obtener el puntaje total del factor (Garcia \& Diaz, 2010) (Ver Anexo 3).

El resultado que se obtiene después de la aplicación de la prueba es analizado desde el enfoque en que a mayor puntaje obtenido el nivel de optimismo es mayor. Esta prueba puede ser administrada de manera individual o colectiva con un promedio de tiempo de cinco minutos para resolverla (Grimaldo, 2004).

En lo que refiere a Perú, se realizó un estudio con este instrumento en 231 estudiantes universitarios de la ciudad de Lima, con el fin de medir el nivel de optimismo en dichos participantes y evaluar las propiedades psicométricas del LOT $-\mathrm{R}$, relacionando el constructo con variables como Satisfacción hacia la vida y Calidad de Vida.

En cuanto a la confiabilidad de las puntuaciones obtenidas en la prueba, se obtuvo un coeficiente Alfa de Cronbach de .61. Posteriormente, se recurrió al método test retestque especificaron las correlaciones .56 para 24 meses y .79 para 28 , siendo ambas mayores a .5; esto quiere decir que los puntajes son estables en el tiempo (Grimaldo, 2004).

La siguiente variable de interés es el afrontamiento, analizada por medio de la Escala de Estrategias de Afrontamiento Modificada (EEC - M), la cual fue construida por Lazarus y Folkman en el año 1984 con el nombre original de "WaysofCopingInstrument, WCI", creada con el objetivo de medir los recursos tanto cognitivos como comportamentales de una persona en situaciones estresantes(Rey \& Jaimes, 2013).

Posteriormente, Chorot y Sandín en el año 1993, realizaron una modificación de la prueba estableciéndole el nombre de EEC - R. Finalmente, Londoño, Henao, Puerta, Posada, Arango y Aguirre - Acevedo realizaron la última versión de esta prueba denominándola "EEC - M", manteniendo el objetivo de la escala (Londoño, y otros, 2006).

Las opciones de respuesta de tipo Likert se han mantenido desde la versión original, que van desde el 1 al 6 (1 Nunca, 2 Casi Nunca, 3 A veces, 4 Frecuentemente, 5 Casi Siempre, 6 Siempre). Esta última presentación de la escala fue validada en Colombia sometida a 893 participantes adultos; en una etapa anterior contenía 98 ítems y 14 componentes entendidos como estrategias de afrontamiento; sin embargo, después de un análisis de componentes principales con rotación Oblimin, se halló un KMO de .89 y una prueba de esfericidad de Barttlet de $.00(\mathrm{p}<.00)$, siendo posible realizar un análisis factorial. A partir de ello los autores llegaron a la conclusión de reducir a 12componentes, 
pues cumplían con losrequisitos de que los factores tenían un valor propio mayor a .1, una confiabilidad de las puntuaciones por encima de .50 y los ítems poseían cargas factoriales mayores a .50(Londoño, y otros, 2006).

La prueba, entonces, se concretó con 69 ítems agrupados en 12 factores (Solución de problemas, Apoyo social, Espera, Religión, Evitación emocional, Apoyo profesional, Reacción agresiva, Evitación cognitiva, Reevaluación positiva, Expresión de la dificultad de afrontamiento, Negación y Autonomía) (Ver Anexo 4).

Estos factores se detallan de la siguiente manera: Solución de problemas, explicada por las acciones que la persona lleva a cabo para resolver dicho problema en el momento preciso mediante técnicas analíticas y racionales; Apoyo social, enfocada a los grupos ya sean de amistades, familiares y otros que ayudan de forma emocional y con información en cuanto al hecho amenazante(Londoño, y otros, 2006).

Otro factor es la Espera, ligado a técnicas cognitivo - conductuales para utilizar las creencias de la persona con el fin de obtener un resultado por sí solo del evento; Religión, orientado a Dios y al rezo para que sean agentes primarios de la intervención y solución del problema. Asimismo, el factor Evitación emocional está referido a la movilización o inhibición de las emociones de carga negativa para la persona; por otro lado, se encuentra el Apoyo profesional, ligado al apoyo de personas expertas en la materia que son capaces de brindar información verificada, lo que proporciona disminución de ansiedad por el evento(Londoño, y otros, 2006).

Sobre el factor Reacción agresiva, es aquella estrategia que se manifiesta desde el impulso de hacerse daño a sí mismo, hacia los demás o algún objeto, pues la ira busca ser liberada para aliviar momentáneamente el estrés; la Evitación cognitiva, busca la distracción para reducir o evitar completamente dicha situación; se encuentra también la Reevaluación positiva, este factor involucra aprender del evento para obtener la mayor gratificación positiva posible sobre éste, por medio de pensamientos favorables (Londoño, y otros, 2006).

Por otro lado, se encuentra el factor Expresión de la dificultad de afrontamiento, éste conceptualiza la tendencia a manifestar las emociones desesperanzadoras sobre la situación y así llegar a encontrar una solución al problema, se comenta que también es valorada como estrategia previa a otras (búsqueda de apoyo social o profesional). El factor Negación también es conocido por la dificultad de no aceptar el hecho como realidad, desvinculándose por un periodo de la situación y continuar como si no existiese el evento amenazante. Por último, el factor Autonomía, se describe como la estrategia en 
la que la persona es capaz de resolver el problema de manera independiente sin el apoyo profesional y social (Londoño, y otros, 2006).

No se han encontrado propiedades psicométricas de esta prueba validadas en el Perú; por esto se decidió trabajar con la versión colombiana explicada anteriormente. Cada ítem está agrupado en factores específicos, mostrados de la siguiente manera:

Tabla 1.

Propiedades psicométricas de esta prueba validadas en el Perú

\begin{tabular}{ll}
\hline Factores & Ítems \\
\hline Factor 1: Solución de Problemas & $10,17,19,26,28,37,39,51$ y 68 \\
Factor 2: Apoyo Social & $6,14,23,24,34,47$ y 57 \\
Factor 3: Espera & $9,18,27,29,38,40,50,60,69$ \\
Factor 4: Religión & $8,16,25,36,49,59$ y 67 \\
Factor 5: Evitación Emocional & $11,20,21,30,41,43,53$ y 62 \\
Factor 6: Apoyo Profesional & $7,15,35,48$ y 58 \\
Factor 7: Reacción Agresiva & $4,12,22,33$ y 44 \\
Factor 8: Evitación Cognitiva & $31,32,42,54$ y 63 \\
Factor 9: Reevaluación Positiva & $5,13,46,56$ y 64 \\
Factor 10: Expresión de la dificultad de & $45,52,55$ y 61 \\
afrontamiento & \\
Factor 11: Negación & 1,2 y 3 \\
Factor 12:Autonomía & 65 y 66 \\
\hline
\end{tabular}

La confiabilidad de las puntuaciones obtenidas en la Escala de Estrategias de Afrontamiento Modificada se presenta con un coeficiente Alfa de Cronbach de .85 y la varianza total acumulada de 58\%, lo que define al factor de "Estrategia de Afrontamiento al Estrés" como representativo de la prueba (Londoño, y otros, 2006).

La escala se califica mediante la suma de los ítems correspondientes de cada estrategia. Una vez obtenidos los puntajes directos se transforman en percentiles para recurrir al baremo en una tabla específica de "Media, desviación y percentiles de la Escala de Estrategias de Coping - Modificada (EEC - M) en una muestra colombiana"(Londoño, y otros, 2006).

Esta prueba, en el presente estudio, se aplicó de manera completa (69 ítems); sin embargo, en el análisis de resultados se eligieron específicamente los factores "Solución de problemas" y "Reevaluación positiva" para consolidar la variable Afrontamiento Activo y los factores "Evitación cognitiva" y "Evitación emocional” para la variable Afrontamiento Evitativo con sus respectivos ítems, pues se tenía el interés de evaluar dichos conceptos en la población de la investigación. Se toma como base el estudio realizado por(Gantiva, Luna, Dávila, \& Salgado, 2010), quienes aplicaron y analizaron 
los componentes completos de la prueba; no obstante, mencionaronsimilitudes en las descripciones teóricas del Afrontamiento Activo y Evitativo con los cuatro factores mencionados, para un entendimiento más amplio en el apartado de su discusión (ver Tabla 2).

Tabla 2.

Afrontamiento Activo y Evitativo con los cuatro factores mencionados

\begin{tabular}{ll}
\hline Factores & \multicolumn{1}{c}{ Ítems } \\
\hline Afrontamiento Activo & $5,10,13,17,19,26,28,37,39,4651,56,64$ y \\
Afrontamiento Evitativo & 68 \\
\hline
\end{tabular}

\subsection{Procedimiento}

Se estableció el contacto telefónico y por correo electrónico con los directores o encargados de los centros de terapia y asociaciones de educación especial de la ciudad de Lima, a quienes se les presentó el tema de investigación, la población a estudiarse y el interés en poderaplicar los instrumentos completos a aquellos padres que acudían a dicho lugar, que cumplan con las características delimitadas para el estudio.

Una vez obtenido el permiso, se coordinó una fecha específica para una reunión con los padres de familia de los lugares contactados. En estos encuentros se les explicaba detalladamente el objetivo del estudio, las instrucciones de los cuestionarios y el tiempo promedio que duraría la aplicación. Fue importante para esto contar con un consentimiento informado en el que podían ellos decidir si participar o no de dicha sesión, para lo cual se necesitaba la firma de cada uno de ellos de estar interesados o no en ser parte de la investigación, guardando total confidencialidad de sus datos (Ver Anexo 1), así como el llenado de una ficha socio -demográfica referente a los datos del participante y en relación a su hijo (Ver Anexo 2).

La muestra fue de 94 personas, se analizó la información por medio del programa SPSS, se organizaron los datos en una base y se elaboró el análisis estadístico según correspondía para cada medida.

Luego de la recolección de datos, los instrumentos fueron analizados en paralelo mediante un análisis de componentes principales que busca sintetizar los datos y relacionarlos entre sí. Para la prueba LOT - R se utilizó rotación varimax, y para la nueva estructura de la escala EEC - M se usó rotación oblimin directo. Esto se dio con el fin de 
obtener coeficientes KMO, Pruebas de esfericidad de Bartlett y así asegurar un próximo análisis factorial.

Desde el lado de la confiabilidad de las puntuaciones se procedió a analizar la consistencia interna de los instrumentos por medio del coeficiente Alfa de Cronbach. Con este método se debía estar al tanto de las puntuaciones del estadístico total - elemento en las correlaciones para así asegurarse de eliminar algún ítem por baja puntuación. Dichas correlaciones, además, han sido reportadas por medio de un rango desde la puntuación menor hasta la mayor.

Después, se analizó la normalidad de las puntuaciones, empleando el estadístico Kolmogorov - Smirnov, para determinar qué coeficiente de correlación se debía emplear para cada variable. 


\section{Capítulo 3. RESULTADOS}

Para investigar la evidencia de validez del Cuestionario de Orientación Vital Revisado (LOT - R) se utilizó el análisis de componentes principales (ACP), tal como se llevó a cabo en el estudio que realizaron sus autores (Sheier, Carver, \& Bridges, 1994).

El resultado de este análisis mostró un coeficiente de Kaiser - Meyer - Olkin (KMO) igual a .56, siendo satisfactorio al estar por encima de .50 (George \&Mallery, 2003) y una Prueba de esfericidad de Bartlett significativa de .00, X2(15) = 73.59 $(\mathrm{p}<.001)$. Esto manifestó que la matriz de correlaciones de los ítems puede someterse a un análisis factorial(Montoya, 2007).

Se realizó la extracción de unfactor; el cual obtuvo un autovalor de 1.92 que explicó el 31.96\% de la varianza total, por lo que su interpretación se realizará de acuerdo a las teorías que así lo confirman (Sheier, Carver, \& Bridges, 1994);(Grimaldo, 2004); (Martínez, Reyes del Paso, García, \& González, 2006);(Mendoza, 2014).

Se encuentran los ítems 1, 3, 4, 7, 9 y 10 dentro de la dimensiónllamada Optimismo Disposicional, con cargas factoriales entre .43 y .66, consideradas como recomendables (Aldás, 2005). A continuación las cargas factoriales pueden observarse de manera más detallada (ver Tabla 3).

Tabla 3.

Matriz de patrón del Cuestionario LOT - R

\begin{tabular}{lc}
\hline Ítems & \multicolumn{2}{c}{ Cargas Factoriales } \\
\cline { 2 - 2 } \multicolumn{1}{c}{ Optimismo Disposicional } & .57 \\
\hline 1. Cuando no sé qué va a suceder, espero lo mejor & .58 \\
4. Soy optimista sobre mi futuro & .66 \\
10. Espero que me ocurran más cosas buenas que malas. & .57 \\
9. Pocas veces me suceden cosas buenas & .55 \\
3. Cuando algo malo puede ocurrirme, & \\
Me sucede. & .43 \\
7. Casi nunca las cosas van como deseo. & \\
\hline
\end{tabular}

Para determinar la confiabilidad de las puntuaciones obtenidas a partir de la aplicación de la prueba LOT - R se realizó un análisis de consistencia interna en el que se halló un coeficiente Alfa de Cronbach de .56 para el componente 
OptimismoDisposicional siendo un nivel cuestionable(George \& Mallery, 2003). Guilford (Oliden, 2013) propone que la consistencia interna de .5 es suficiente para estudios básicos, en este caso el LOT-R cumple con ello pues se investiga conceptos generales y globales, como lo es el optimismo.

Las correlaciones ítem - test corregidas oscilaron entre .23 y .39, los ítems 1,4 y 7 no superaron el mínimo corte aceptable de .30 (Ver Tabla 4); sin embargo, se decidió no eliminar los ítems, pues se recomienda tener entre tres a cuatro ítems como mínimo para tener cierta estabilidad en los resultados, más aun cuando la cantidad de participantes es inferior a 150 (Costello \& Osborne, 2005).

Tabla 4.

Estadístico total elemento del cuestionario LOT - R

\begin{tabular}{lc}
\hline \multirow{2}{*}{ Ítem } & $\begin{array}{c}\text { Correlación ítem-test } \\
\text { corregida }\end{array}$ \\
\cline { 2 - 2 } & $\begin{array}{c}\text { OptimismoDisposicional } \\
\text { 1. Cuando no sé qué va a suceder espero lo mejor. }\end{array}$ \\
10. Espero que me ocurran más cosas buenas que malas. & .23 \\
4. Soy optimista sobre mi futuro. & .28 \\
7. Casi nunca las cosas van como deseo. & .25 \\
3. Cuando algo malo puede ocurrirme, me sucede. & .33 \\
9. Pocas veces me suceden cosas buenas. & .39 \\
\hline
\end{tabular}

Para la nueva estructura utilizada de la Escala de Estrategias de Afrontamiento Modificada (EEC-M), se realizó un análisis de componentes principales (ACP) con rotación Oblimin. Se obtuvo un coeficiente de Kaiser - Meyer - Olkin (KMO) igual a $.69 y$ una Prueba de esfericidad de Bartlett significativa de .00, X2 (351) $=971.58$ $(\mathrm{p}<.001)$, mostrando que la matriz de correlaciones puede someterse a un análisis factorial (Montoya, 2007).

Dicho análisis arrojó dos componentes; el primero de ellos obtuvo un autovalor de 5.42 que explicó el 20.08\% de la varianza, en éste se encuentran los ítems 5, 10, 13, 17, 19, 26, 28, 37, 39, 46, 51, 56, 64 y 68 etiquetado como Afrontamiento Activo, con cargas factoriales entre .29 y .70; el segundo componente obtuvo un autovalor de 3.29que explicaba el 12.17\% de la varianza, encontrándose en éste los ítems 11, 20, 21, 30, 31, 32, 41, 42, 43, 53, 54, 62, 63, llamado Afrontamiento Evitativo, con cargas factoriales entre .16 y .78; Estos dos componentes explican el 32.25\% de la varianza total. (Ver Tabla 5) 
Tabla 5.

Cargas factoriales de los ítems de la nueva estructura de la prueba EEC-M

\begin{tabular}{|c|c|c|}
\hline \multirow[b]{2}{*}{ Ítems } & \multicolumn{2}{|c|}{ Componentes } \\
\hline & $\begin{array}{l}\text { Afrontamiento } \\
\text { Activo }\end{array}$ & $\begin{array}{l}\text { Afrontamiento } \\
\text { Evitativo }\end{array}$ \\
\hline $\begin{array}{l}\text { 28. Hago frente a un problema, espero conocer } \\
\text { bien la situación antes de actuar. } \\
68 \text {. Frente a un problema, espero conocer bien }\end{array}$ & .70 & \\
\hline la situación antes de actuar. & .69 & \\
\hline 64. Trato de identificar las ventajas del problema & .67 & \\
\hline $\begin{array}{l}\text { 13. Intento sacar algo positivo del problema } \\
\text { 51. Analizo lo positivo y negativo de las diferentes }\end{array}$ & .65 & \\
\hline alternativas. & .63 & \\
\hline $\begin{array}{l}\text { 5. Intento ver los aspectos positivos del problema } \\
\text { 39. Pienso detenidamente los pasos a seguir para }\end{array}$ & .61 & \\
\hline $\begin{array}{l}\text { enfrentarme al problema. } \\
\text { 46. A pesar de la magnitud de la situación tiendo }\end{array}$ & .58 & \\
\hline $\begin{array}{l}\text { a sacar algo positivo. } \\
\text { 56. Tengo muy presente el dicho "al mal tiempo }\end{array}$ & .56 & \\
\hline $\begin{array}{l}\text { buena cara". } \\
\text { 26. Pienso que hay un momento oportuno para }\end{array}$ & .52 & \\
\hline $\begin{array}{l}\text { analizar la situación } \\
\text { 17. Espero el momento oportuno para resolver }\end{array}$ & .45 & \\
\hline $\begin{array}{l}\text { el problema } \\
\text { 19. Establezco un plan de actuación y procuro }\end{array}$ & .45 & \\
\hline $\begin{array}{l}\text { 1levarlo a cabo. } \\
\text { 10. Trato de solucionar el problema siguiendo }\end{array}$ & .44 & \\
\hline $\begin{array}{l}\text { Unos pasos concretos bien pensados. } \\
\text { 37. Hasta que no tenga claridad frente a la situación. }\end{array}$ & .35 & \\
\hline $\begin{array}{l}\text { no puedo darle la mejor solución a los problemas. } \\
53 \text {. Hago todo lo posible para ocultar mis sentimientos }\end{array}$ & .29 & \\
\hline a los otros. & & .78 \\
\hline 30. Trato de ocultar mi malestar & & .68 \\
\hline $\begin{array}{l}\text { 20. Procuro que los otros no se den cuenta de lo que } \\
\text { siento. }\end{array}$ & & .65 \\
\hline $\begin{array}{l}\text { 43. Niego que tengo problemas. } \\
\text { 41. Inhibo mis propias emociones. }\end{array}$ & & .64 \\
\hline 62. Trato de evitar mis emociones. & & .62 \\
\hline 11. Procuro guardar para mí los sentimientos & & .55 \\
\hline $\begin{array}{l}\text { 54. Me ocupo de muchas actividades para no pensar } \\
\text { en el problema. }\end{array}$ & & .50 \\
\hline $\begin{array}{l}\text { 21. Evado las conversaciones o temas que tienen que } \\
\text { ver con el problema. }\end{array}$ & & .44 \\
\hline 42. Busco actividades que me distraigan. & & .36 \\
\hline 63. Dejo a un lado los problemas y pienso en otras cosas & & .35 \\
\hline $\begin{array}{l}\text { 31. Salgo al cine, a dar una vuelta, etc., para olvidarme } \\
\text { del problema. }\end{array}$ & & .17 \\
\hline 32. Evito pensar en el problema. & & .16 \\
\hline
\end{tabular}


Tal como se aprecia en la Tabla 3 los ítems 10, 31, 32, 37, 42 y 63 comprenden cargas factoriales menores a .4 , se recomienda eliminar dichos ítems por las bajas puntuaciones que presentan(Williams, Brown, \& Onsman, 2010).

Luego de ello, se siguió con la confiabilidad de las puntuaciones obtenidas para corroborar que la nueva cantidad de ítems es adecuada y estable. Al realizarse los análisis se obtuvo un coeficiente Alfa de Cronbach de .83 para Afrontamiento Activo con una correlación total de elementos corregida entre .42 y .56; para Afrontamiento Evitativo se obtuvo un coeficiente Alfa de Cronbach de .81con una correlación total de elementos corregida entre .28 y .50, se observó que el ítem 54 tenía la correlación total de elementos corregida más baja, afectando el coeficiente Alfa de Cronbach del componente, por ello se decidió eliminar el ítem. Se realizó un nuevo análisis factorial para comprobar si la nueva estructura de los componentes era válida; las cargas factoriales para el componente Afrontamiento Activo oscilaban entre .42 y .70, para el componente Afrontamiento Evitativo estaban entre .45 y .82 (Ver Tabla 6). Se decidió proseguir con esta nueva estructura (Ver Anexo 5).

Tabla 6.

Cargas factoriales de los ítems de la prueba EEC-M 


\begin{tabular}{|c|c|c|}
\hline \multirow[b]{2}{*}{ Ítems } & \multicolumn{2}{|c|}{ Componentes } \\
\hline & $\begin{array}{l}\text { Afrontamiento } \\
\text { Activo }\end{array}$ & $\begin{array}{l}\text { Afrontamiento } \\
\text { Evitativo }\end{array}$ \\
\hline $\begin{array}{l}\text { 28. Hago frente a un problema, espero conocer } \\
\text { bien la situación antes de actuar. } \\
68 \text {. Frente a un problema, espero conocer bien }\end{array}$ & .70 & \\
\hline la situación antes de actuar. & .69 & \\
\hline 64. Trato de identificar las ventajas del problema & .70 & \\
\hline $\begin{array}{l}\text { 13. Intento sacar algo positivo del problema } \\
51 \text { Analizo lo positivo y negativo de las diferentes }\end{array}$ & .63 & \\
\hline alternativas. & .62 & \\
\hline $\begin{array}{l}\text { 5. Intento ver los aspectos positivos del problema } \\
\text { 39. Pienso detenidamente los pasos a seguir para }\end{array}$ & .60 & \\
\hline $\begin{array}{l}\text { enfrentarme al problema. } \\
\text { 46. A pesar de la magnitud de la situación tiendo }\end{array}$ & .57 & \\
\hline $\begin{array}{l}\text { a sacar algo positivo. } \\
56 \text {. Tengo muy presente el dicho "al mal tiempo }\end{array}$ & .55 & \\
\hline $\begin{array}{l}\text { buena cara". } \\
\text { 26. Pienso que hay un momento oportuno para }\end{array}$ & .56 & \\
\hline $\begin{array}{l}\text { analizar la situación } \\
\text { 17. Espero el momento oportuno para resolver }\end{array}$ & .46 & \\
\hline $\begin{array}{l}\text { el problema } \\
\text { 19. Establezco un plan de actuación y procuro }\end{array}$ & .47 & \\
\hline $\begin{array}{l}\text { llevarlo a cabo. } \\
\text { 53. Hago todo lo posible para ocultar mis sentimientos }\end{array}$ & .42 & \\
\hline a los otros. & & .82 \\
\hline 30. Trato de ocultar mi malestar & & .72 \\
\hline $\begin{array}{l}\text { 20. Procuro que los otros no se den cuenta de lo que } \\
\text { siento. }\end{array}$ & & .72 \\
\hline 43. Niego que tengo problemas. & & .57 \\
\hline 41. Inhibo mis propias emociones. & & .65 \\
\hline 62. Trato de evitar mis emociones. & & .64 \\
\hline 11. Procuro guardar para mí los sentimientos & & .58 \\
\hline $\begin{array}{l}\text { 21. Evado las conversaciones o temas que tienen que } \\
\text { ver con el problema. }\end{array}$ & & .45 \\
\hline
\end{tabular}

Se analizó la confiabilidad de las puntuaciones obtenidas del primer componente (Afrontamiento Activo), arrojando un coeficiente Alfa de Cronbach de .83, mientras que el segundo componente (Afrontamiento Evitativo) obtuvo .81, ambos buenos(George \& Mallery, 2003). El rango de la correlación total de elementos corregida que manejaba el factor de Afrontamiento Activo estaba entre .33 y .63 (ver Tabla 7), mientras que para el factor Afrontamiento Evitativo se encontraba entre .38 y .72 (ver Tabla 8).

Tabla 7.

Correlación elemento total - corregida del componente Afrontamiento Activo 


\begin{tabular}{lc}
\hline Items & Correlación elemento-total corregida \\
\hline 68. Frente a un problema, espero conocer & .63 \\
bien la situación antes de actuar. & .60 \\
28. Hago frente al problema poniendo & .58 \\
en marcha varias soluciones. & \\
64. Trato de identificar las ventajas del problema. & .52 \\
39. Pienso detenidamente los pasos a seguir & .50 \\
para enfrentarme al problema. & .50 \\
13. Intento sacar algo positivo del problema. & .49 \\
26. Pienso que hay un momento oportuno para & \\
analizar la situación. & .47 \\
56. Tengo muy presente el dicho "al mal tiempo buena cara". \\
51. Analizo lo positivo y negativo de las & .45 \\
diferentes alternativas. & .43 \\
5. Intento ver los aspectos positivos del problema & \\
17. Espero el momento oportuno para resolver & .38 \\
el problema. & .33 \\
46. A pesar de la magnitud de la situación tiendo & \\
A sacar algo positivo. & \\
19. Establezco un plan de actuación y procuro & \\
llevarlo a cabo. &
\end{tabular}

Tabla 8.

Correlación elemento total - corregida del componente Afrontamiento Evitativo

\begin{tabular}{lc}
\hline Items & Correlación elemento total - corregida \\
\hline 53. Hago todo lo posible para ocultar & .72 \\
mis sentimientos a los otros & .61 \\
30. Trato de ocultar mi malestar & .64 \\
20. Procuro que los otros no se den & .48 \\
cuenta de lo que siento. & .52 \\
41. Inhibo mis propias emociones & \\
11. Procuro guardar para mí los & .43 \\
sentimientos. & .46 \\
43. Niego que tengo problemas. & .38 \\
62. Trato de evitar mis emociones. & \\
21. Evado las conversaciones o temas & \\
que tienen que ver con el problema. &
\end{tabular}

Se presentan los estadísticos descriptivos de las escalas trabajadas con respecto a los 94 participantes: Para la escala de Optimismo Disposicional los puntajes oscilan entre 2 y 5 puntos, el puntaje promedio se acerca al máximo y se presenta, además, una desviación estándar de .68. Para la Escala de Afrontamiento Activo los puntajes se encuentran entre 33 y 72, mientras que para la Escala de Afrontamiento Evitativo están entre 9 y 42. Se observa que existe un menor grado de dispersión para el componente de Afrontamiento Activo (Ver Tabla 9). 
Tabla 9.

Estadísticos descriptivos para el componente Optimismo Disposicional, Afrontamiento Activo y Afrontamiento Evitativo

\begin{tabular}{lccll}
\hline & Mín - Máx & M & D.E & C.V \\
\hline Optimismo Disposicional & $2-5$ & 3.86 & .68 & $17.62 \%$ \\
Afrontamiento Activo & $33-72$ & 52.96 & 8.16 & $15.41 \%$ \\
Afrontamiento Evitativo & $9-42$ & 24.32 & 7.07 & $29.07 \%$ \\
\hline
\end{tabular}

Nota: $\mathrm{M}=$ media; D.E.=desviación estándar; C.V.=coeficiente de variación

Para seguir con el análisis de datos se realizó la prueba de Kolmogorov - Smirnov para una muestra, con el fin de conocer si los datos de las variables se distribuyen normalmente(Field, 2009). El análisis arrojó un KS de .12 para los datos sobre Optimismo Disposicional, con un nivel de significancia de $.00(\mathrm{p}<.05)$, lo que indica que sus datos no se encuentran distribuidos con normalidad. Para el componente de Afrontamiento Activo, éste arroja un KS de .05 con un nivel de significancia de .2 ( $\mathrm{p}>.05)$, lo cual indica que sus datos se distribuyen con normalidad, finalmente el componente de Afrontamiento Evitativo arroja un puntaje KS de .09, con un nivel de significancia de .04 ( $p<.05)$, lo que refiere que sus datos no se distribuyen con normalidad. Al realizar el análisis se decide que se utilizarán pruebas no paramétricas para analizar la correlación entre las variables, específicamente la prueba de Spearman (Field, 2009).

A partir del análisis entre las variables psicológicas se encontró que existe una correlación significativa y positiva entre el Optimismo Disposicional y el Afrontamiento Activo ( $r h o=.31 ; \mathrm{p}=.00$ ), esto quiere decir que a mayor optimismo del padre o madre mayorserásu afrontamiento activo frente a las experiencias que involucren la condición de su hijo, mientras que existe una relación negativa no significativa entre el optimismo y el afrontamiento evitativo ( $\left(\mathrm{hho}^{-}=.04 ; \mathrm{p}=.74\right)$.

Para evaluar los datos en cuanto a los padres y madres que llevaban terapia actualmente y los que no tenían acceso a ella con respecto a las variables (Optimismo y Afrontamiento), se realizó una prueba de normalidad para dirigir los análisis específicos. Los datos de la dimensión de Optimismo Disposicional frente a los padres que sí llevan terapiaarrojaron un KS de .09 y un nivel de significancia de .18 (p>.05), por lo que sí poseen una distribución normal;en cuanto a los padres que no llevan terapia, se obtuvo un KS de .19 y un nivel de significancia de $.03(\mathrm{p}<.05)$, quiere decir que los datos no se distribuyen de manera normal, estas referencias llevaron a que se realice bajo la prueba 
U de Mann Whitney. Para la escalade Afrontamiento Activofrente a los padres que sí acudían a terapia, se obtuvo un KS de .06 y un nivel de significancia de .20 (p>.05), es decirsí poseen una distribución normal, al igual que los que no iban a terapia, donde se obtuvo un KS de .12 y un nivel de significancia de .20 ( $\mathrm{p}>.05)$, por lo tanto se utilizará la prueba T de Student. Finalmente, para el componente de Afrontamiento Evitativo frente a los datos de los padres que acudían a terapia se obtuvo un KS de .08 y un nivel de significancia de .20 ( $>>.05)$, y sobre los datos de aquellos que no acudían a terapia se obtuvo un KS de .14 y un nivel de significancia de .20 ( $>>.05)$, los datos se distribuyen con normalidad, y por ello se utilizará la prueba T de Student.

En cuanto al Optimismo y el acceso a las terapias que tenían los padres dio como resultado que no existen diferencias estadísticamente significativas entre los padres que llevan terapia actualmente y los que no tienen acceso a ella $(\mathrm{U}=846.50 ; \mathrm{p}=.89)$. Del mismo modo no existen diferencias estadísticamente significativas entre que los participantes estén dentro de un proceso terapéutico o no en relación al Afrontamiento Activo $(\mathrm{t}=.80$; $\mathrm{p}=.43)$ y Afrontamiento Evitativo( $(\mathrm{t}=-1.74 ; \mathrm{p}=.09)$.

Para determinar los análisis que se debían hacer con respecto a la ocupación actual de los padres en relación a las variables, se realizó nuevamente la prueba de KolmogorovSmirnov, el cual arrojó que se utilizarían pruebas no paramétricas (U de Mann-Withney) para Optimismo, $(\mathrm{p}<.05)$ y Afrontamiento Evitativo $(\mathrm{p}<.05) ;$ mientras que se utilizaránpruebas paramétricas ( $\mathrm{T}$ de Student) para Afrontamiento Activo ( $\mathrm{p}>.05)$ (Ver Tabla 10). 
Tabla 10.

Prueba de Normalidad de la Ocupación Actual con las variables psicológicas

\begin{tabular}{llcc}
\hline \multirow{2}{*}{ Ocupación Actual } & & \multicolumn{2}{c}{ Kolmogorov-Smirnov } \\
\cline { 3 - 4 } & & Estadístico & Significancia \\
\hline Optimismo Disposicional & Casa & .12 & .04 \\
& Oficina & .14 & .03 \\
Afrontamiento Activo & Casa & .08 & .20 \\
& Oficina & .09 & .20 \\
Afrontamiento Evitativo & Casa & .13 & .02 \\
& Oficina & .07 & .20 \\
\hline
\end{tabular}

Los datos arrojaron que no existen diferencias estadísticamente significativas entre la ocupación actual de los padres en relación al Optimismo que posean ( $U=1006.50$; $\mathrm{p}=.51)$ ni tampoco al Afrontamiento Evitativo $(\mathrm{U}=1083 ; \mathrm{p}=.95)$; esto quiere decir que las funciones que ellos realizan, sean en casa o en oficina, no repercuten en la manera de percibir y afrontar las diferentes situaciones en las cuales también involucren la convivencia con la condición de su hijo.

Por otro lado, no existen diferencias estadísticamente significativas en relación al afrontamiento activo y el tener labores dentro del hogar $u$ oficina $(t=1.00 ; p=.32)$, es decir que la manera de afrontar las situaciones que se presenten no se ve modificadallevando funciones en lugares de trabajo diferentes, sea en casa o fuera de ella.

Los datos referentes a la edad de los padres frente a las variables psicológicas se analizaron por medio de una prueba de normalidad; en cuanto al optimismose obtuvo un KS de .12 y un nivel de significancia de $.00(p<.05)$ y en cuanto a afrontamiento evitativo se obtuvo un KS de .09 y un nivel de significancia de $.04(\mathrm{p}<.05)$ se determinó que se usarían pruebas no paramétricas, es decir una correlación Spearman; mientras que para la variable afrontamiento activo se llevarían pruebas paramétricas, pues arrojó un KS de .05 y un nivel de significancia de .20 ( $>>.05)$, siendo una correlación de Pearson. Como resultado, se obtuvo que existe una correlación significativay positiva entre la edad de los padres y el optimismo que experimentan $(r h o=.25 ; \mathrm{p}=.02)$, esto quiere decir que a mayor edad se tiende a percibir de manera más positiva las experiencias que involucran, también, la convivencia con la condición de autismo en el menor. En contraste, no existe 
correlación entre la edad de los padres y el afrontamiento activo $(r=-.05 ; \mathrm{p}=.60)$ ni evitativo de los mismos ( $\mathrm{rho}=-.12 ; \mathrm{p}=.23)$.

Por último, se analizó el tiempo de convivencia que tenían los padres con la condición del menor, considerando la edad del niño desde el momento del diagnóstico hasta la actualidad; esta convivencia se analizó en relación a las variables psicológicas del estudio, para ello se realizó una prueba de normalidad para saber si correspondían correlaciones paramétricas o no paramétricas. En cuanto a la variable optimismose obtuvo un KS de .12 y un nivel de significancia de $.00(\mathrm{p}<.05)$, la variable afrontamiento evitativo arrojó un KS de .09 y un nivel de significancia de $.04(\mathrm{p}<.05)$, por lo tantose llevaron pruebas no paramétricas. En cuanto a la variable afrontamiento activo se realizaron pruebas paramétricas, pues se obtuvo un KS de .05 y un nivel de significancia de .20 ( $\mathrm{p}>.05)$, al obtener los datos de todas las variables se concluyó utilizar una correlación de Spearman. Los resultados arrojan que existe una correlación significativay positiva entre el tiempo de convivencia con el autismo y el optimismo de los padres (rho=.23; $\mathrm{p}=.03$ ), quiere decir que a mayor tiempo conviviendo con un hijo diagnosticado con autismo, el nivel de optimismo del padre será más alto. 


\section{Capítulo 4. DISCUSION}

La evidencia de validez del Cuestionario de Orientación Vital - Revisado (LOT R) se realizó por medio del análisis de componentes principales con rotación Varimax (Field, 2009).

Se realizóa partir de sólo un componente (OptimismoDisposicional), siendo utilizado por diferentes autores (Grimaldo, 2004);(Marrero \& Carballera, 2010);(Mera \& Ortiz, 2012);(Cano, y otros, 2015);(Mendoza, 2014); Chacón, Rodríguez, García, Antuña\& Pérez, 2015;(Medina, 2017) para medir las expectativas positivas de cada población en interés. Asimismo, un estudio realizado por (Landero \& Gonzáles, 2009)con pacientes diagnosticados con fibromialgia sugería el trabajo con un solo factor para mayor estabilidad de los datos.

La confiabilidad de las puntuaciones obtenidas en dicha escala en el presente estudio arrojó un coeficiente Alfa de Cronbach de .56, el cual se considera cuestionable(George \& Mallery, 2003); Asimismo, se encontró otro estudio en Perú que emplea el instrumentodirigido a padres de niños con TEA(Mendoza, 2014)el cual arrojó un coeficiente Alfa de Cronbach de .39. Por otro lado,(Oliden, 2013)en su investigación obtiene un coeficiente Alfa de Cronbach de .55 para el factor Optimismo. La investigación realizada por(Grimaldo, 2004) en Lima obtuvo, por su lado, un coeficiente Alfa de Cronbach de .61 que indica ser cuestionable (George \& Mallery, 2003).No obstante, Guilford (Oliden, 2013)propone que la consistencia interna de .50 es suficiente para estudios básicos, en este caso el LOT-R investiga conceptos generales y globales, como es el Optimismo. De igual forma, estos resultados pueden deberse a la poca cantidad de ítems que contiene la prueba (6 ítems), también a que el tamaño de la muestra no es grande, pues se sabe que a mayor cantidad de participantes existe mayor variabilidad en las respuestas y por lo tanto la confiabilidad de las puntuaciones sea también más alta (Morales, 2007).

Para la evidencia de validez de la nueva estructura de Escala de Estrategias de Afrontamiento Modificada (EEC - M) se realizó por medio del análisis de componentes principales con rotación Oblimin (Field, 2009), pues supone que los factores están fuertemente correlacionados. Los ítems de la escala fueron englobados en dimensiones.E1 análisis de estos arrojó 2 componentes refiriéndose a Afrontamiento Activo y 
Afrontamiento Evitativo. Del mismo modo, el gráfico de sedimentación corroboró que los 20 ítems seleccionados se agrupan en dos factores.

Para el factor Afrontamiento Activo se obtuvo un coeficiente Alfa de Cronbach de .83 considerada buena, mientras que para el factor Afrontamiento Evitativo fue de .81 manteniéndose también en un nivel bueno(George \& Mallery, 2003).

Esta escala ha sido utilizada en diferentes poblaciones y variables de interés, como investigaciones en relación al afrontamiento de padres de niños con trastorno del espectro autista (Albarracin, Rey, \& Jaimes, 2014)también, fue utilizada con adolescentes en relación a la depresión (Gómez \& Porras, 2010). Por otro lado, se empleó para analizar el afrontamiento utilizado en recaídas de adolescentes que consumían sustancias psicoactivas(Nieto, 2012).

Los resultados indicaron que existe una correlación significativa y positiva entre el optimismo disposicional y el afrontamiento activo del progenitor, quiere decir que aquellos padres que tengan una visión más positiva del futuro, tenderán a emplear recursos más directos para resolver alguna situación que les genere estrés.(Pozo, 2010)evidencia, con variables similares, que los padres y madres de personas con autismo presentan un alto nivel de sentido de coherencia y de bienestar psicológico,pues comprenden la situación y la consideran retadora, buscando resolver dichos eventos con acciones y metas planificadas, como la ayuda externa, la auto - aceptación y el humor. Del mismo modo,(Morales N. , 2013) explica que cuando no se concibe como limitante al diagnóstico, sino como una experiencia para fortalecerse como individuo y a nivel familiar ha llevado a los padres a indagar más sobre el autismo, conocer testimonios y buscar apoyo social y emocional con el fin de impactar positivamente en el desarrollo del menor. Datos similares se encuentran en el estudio de (Herrera \& Cuervo, 2017), en el que las madres que han aceptado y asumido la realidad, han podido reorganizar sus prioridades y las herramientas útiles para desarrollar el potencial de su hijo con habilidades diferentes; por lo tanto no lo experimentan como una vivencia negativa, sino como una oportunidad para crecer personalmente y para motivarse diariamente a fin de experimentar cambios a favor de ellos.

Por su lado, (Garcia \& Pérez, 2016),mencionan en su estudio dirigido al uso de recursos como el "mindfulness", que los padres con mayor resiliencia afrontan y superan mejor los desafíos que presenta tener un hijo con autismo en comparación que aquellos que no pueden controlar el estrés que genera la situación; esto impacta de manera positiva a su vida como esposos y/o en la interacción con su hijo y familiares. Autores como 
(Maseda, 2015), (Herrera \& Cuervo, 2017), presentan sus resultados señalando que los padres que poseen más confianza en sí mismos, aquellos que buscan actividades para su desarrollo personal y son más independientes, tienden a llevar un afrontamiento más adaptativo y saludable, ya que el encontrar tiempo de ocio y desconexión breve de la problemática elevan la energía para sobrellevar la crianza del menor. Asimismo, influye de manera fundamental la percepción positiva que se tiene de la realidad; es decir, encontrar un sentido a la adversidad y construir una fortaleza interna activará recursos adecuados para alcanzar objetivos a corto, mediano y largo plazo dentro de la dinámica familiar.

El autismo en el contexto familiar supone de un grado de estrés mayor al que tendría otro sin dicha variable(Martínez, M. y Bilbao, M., 2008); sin embargo, aquellas personas que con frecuencia han tenido expectativas más positivas hacia el futuro, al momento de asimilar un diagnóstico de autismo en su hijo tenderán a desenvolverse y actuar de manera más saludable y activa al tratamiento necesario.

Se evidenció una relación negativa no significativa entre el optimismo disposicional y el afrontamiento evitativo de los padres, lo cual mantiene la afirmación de los estudios mencionados anteriormente, que mientras las expectativas a futuro sean positivas las acciones concretas serán más reales y se llevarán a cabo.

Por otro lado, en el presente estudio no se encontraron diferencias estadísticamente significativas entre el optimismo y afrontamiento con los datos referentes a llevar terapia o no a la actualidad; sin embargo, en otras investigaciones como la de (Campbell \& Figueroa, 2000), los padres de niños diagnosticados con TEA que llevaban reuniones para compartir experiencias y comentar sobre los casos individuales demostraban una mejor comprensión de la condición de su propio hijo; si bien, no era monitoreado por un especialista profesional, se expone el alivio de sentirse acompañados por padres con mayor experiencia en la condición de autismo. Fomentar espacios de intercambio, de escucha y aprendizaje son fundamentales para los padres o cuidadores de una persona con habilidades diferentes, pues de esta manera no sólo incorporarán nuevas estrategias para la crianza con el menor, sino que se complementará con la experiencia de otro en la misma situación y/o del profesional que está a cargo(Maseda, 2015).Otro estudio constata, también, la importancia del apoyo profesional hacia los padres, indicando que la carga emocional que trae la atención hacia sus hijos con discapacidad intelectual debe estar apoyada en contención y orientación, más aun en las etapas iniciales. Del mismo modo, se afirmó la relevancia no sólo de sesiones presenciales de 
atención psicológica y psiquiátrica, sino de un servicio en línea que pueda estar disponible en cualquier momento y de poder formar grupos de padres con hijos de similar diagnóstico para llevar actividades recreativas, un espacio de desconexión y apoyo entre todoslos involucrados(MarcadorDePosición1)(Giné, Balcells, Simó, \& Font Roura, 2011). Si bien la disparidad en la cantidad de participantes pudo haber influido en los resultados no significativos en cuanto a los que llevaban (69 participantes) y no llevaban terapia actual(25 participantes) en el presente estudio, se han considerado estas otras investigaciones pues se cree importante incluirlas en posteriores estudios que contengan datos más equilibrados entre el número de encuestados las evidencias que se exponen.

Además, se señaló que a mayor edad de los padresel nivel de optimismo se incrementa.Cierta similitud en cuanto al paso del tiempo se encuentraen un estudio realizado por Kausar, Jevne y Sobseycitado en(Pozo \& Sarriá, 2015)en el que se analizaron cualitativamente los discursos de padres de un hijo con autismo, concluyendo que a lo largo de su vida han empoderado sus capacidades personales, redefinido el rol que cumplen como padres, así como el aumento de sus esperanzas, expectativas y determinación para encontrar recursos a las necesidades de sus hijos. Además, (Gray, 2006)expone que a mayor edad del padre de la persona con autismo, mayor será el uso de estrategias centradas en la emoción y valorará de forma más positiva la condición de su hijo. Otra investigación arroja que los padres de niños de mayor edad puntuaban más alto en resiliencia que los de menor edad; si bien, no fue significativo, da luces de esta capacidad dinámica y positiva que se puede desarrollar a lo largo del tiempo (Jiménez, 2016)

Sin embargo, también se exponen resultados contrarios, en el que los padres de mayor edad de las personas adolescentes o adultas con autismo empiezan a experimentar niveles de estrésmás elevados que los padres de personas menores, pues notan que la limitada independencia que puedan llegar a tener es preocupante para concretar una vida segura cuando los progenitores ya no puedan hacerse cargo de ellos, a esto se le suma el peso y talla mayor que dificulta poder controlar alguna crisis conductual que pueda presentarse en el hogar (Navarro, 2008). Sin embargo estas sensaciones de los padres varía de acuerdo al país donde habiten, pues en algunas ciudades desarrolladas, se cuenta con espacios de acogimiento para personas con alguna discapacidad que no tengan cuidadores cercanos; esto definitivamente alivia el estrés y aumenta la satisfacción de los padres (Hunter, 2013). 
Por último, se evidencia que existe una correlación positiva y significativa entre el nivel de optimismo del padre y el tiempo de convivencia con el autismo; quiere decir que a medida que transcurren los años junto al hijo con autismo, los padres adoptan mayores niveles de optimismo. (Morales N. , 2013), pone de manifiesto que laresilienciasobre los acontecimientos que uno ha vivido llevará a utilizar ciertos recursos para su vida actual frente al cuidado del menor; Asimismo, señala que las familias que están expuestas más tiempo a la convivencia con un integrante con TEA comprenden que esta persona es parte de la sociedad, que no hay motivos para sentirse avergonzado ni culpable de la situación. Además, se encontraron resultados que las madres de niños con autismo diagnosticados hace 18 meses, tendían a adaptarse mejor a las situaciones de estrés y presentaban menores síntomas psicológicos que aquellas madres que recién confirmaban el diagnóstico en sus hijos, las cuales buscaban evitar pensar y/o actuar frente al evento(Rubia, 2011)

Es importante resaltar que también existen estudios contrarios que resaltan la intranquilidad que experimenta el cuidador de una persona con autismo, pues se encuentranen constante exposición a los cambios de conducta, hiperactividad y en ciertos casos niveles de agresividad visibles en diferentes etapas del desarrollo del menor(Ruiz, Antón, González, \& Moya, 2012). Ciertos estudios exponen la diferencia entre la sintomatología típica del autismo y los comportamientosparalelos disruptivos; estos últimos comportamientos pueden ser el predictor del nivel de estrés que presente el cuidador(Lecavalier, Leone, \& Wiltz, 2006); (Barker, y otros, 2011)mientras que la sintomatología típica de la condición está más orientado al grado de bienestar en los cuidadores(Epstein, Saltzman Benaiah, O'Hare, Goll, \& Truck, 2008); (Khanna, y otros, 2010).

Cabe resaltar que no se han realizado estudios con ambas variables juntas en padres de niños con autismo (Optimismo y Afrontamiento), por lo que estos resultados podrían aportar teóricamente y repercutir en la toma de consciencia e intervención de los padres hacia el desarrollo y estimulación de sus hijos, así como en el plan de acción llevado por los centros de educación especial enfocados en charlas o Escuela de Padres. Relacionar una variable desde el ámbito positivo con el afrontamiento conlleva a pensar en este ámbito más saludable del esfuerzo; reconocer que las experiencias se interpretan como beneficiosas por el valor que el mismo progenitor da a los éxitos del proceso mismo, más que al alcance del objetivo específico (Benites, 2010);(Suriá, 2014)Se menciona esto pues, es recurrente encontrar estudios enfocados en el estrés o depresión en los padres o 
cuidadores de niños con autismo(Pozo, Sarria, \& Méndez, Estrés en madres de personas con trastornos del espectro autista. Psicothema, 2006);(Seguí, Ortiz Tallo, \& Diego, 2008);(Basa, 2010); (Ayuda, Llorente, Martos, Rodríguez, \& Olmo, 2012);(Pineda, 2012); (Ramírez \& Mogollón, 2013);(Álvarez \& Joancely, 2014);(Del Cid, 2016); sin embargo, la línea adaptativa o positiva de convivir con la condición del menor no ha sido estudiada en su magnitud. Esta investigación, justamente, busca replantear y analizar este nuevo panorama de los padres de niños con autismo y la repercusión en ellos con una mirada alentadora, en la que su actitud y expectativas positivas tenderán a desprender actividades más precisas y de impacto hacia el desenvolvimiento del menor tanto en el hogar, centro de educación y sociedad.

Importante comentar que dicho optimismo de los padres puede ser clave para involucrarse más en el entendimiento y empatía frente a la persona diagnosticada, ya que crear expectativas positivas requiere de un mayor acercamiento a la situación; así como lo mencionan (Martínez, M. y Bilbao, M., 2008), poder mirar la realidad con los mismos ojos del menor hará que se comprendan de mejor manera los comportamientos que se presentan en el autismo. Dicha comprensión no llega sola, sino es fundamental el acompañamiento de profesionales debidamente preparados para que puedan compartir información certera, precisa y entendible a las familias involucradas(Giné, Balcells, Simó, \& Font Roura, 2011).

Se pudo concluir que existe relación entre el optimismo y el afrontamiento activode los padres, lo cual quiere decir que a mayor optimismo que presente el progenitor tenderá a afrontar de manera activa las situaciones de estrés que podrían derivarse en la convivencia con la condición de autismo en su hijo y que lo llevarían a emplear estrategias que se orienten al pronto tratamiento de acciones directas como buscar apoyo profesional y social, realizar un plan de acción, etc.

Este estudio busca tener repercusión en diferentes ámbitos, como en el personal pues cada padre o tutor que esté sobrellevando una situación similar a la expuesta podrá reconocer aspectos individuales en su forma de ver la vida y las herramientas que tiene a su disposición, generando una mirada más amplia hacia toda la vivencia y no sólo a los aspectos más adversos. Además, desde el ámbito social, el apoyo que existe alrededor de las personas involucradas es fundamental para el sostenimiento de cada integrante de la familia, de manera que no sólo se centre la atención en el niño diagnosticado, sino también en los padres, como pilares del desarrollo del menor; teniendo en cuenta la salud mental que se necesita de ellos, pues supone una carga emocional dura que muchas veces puede 
esconderse por temores, vergüenza o autosuficiencia de alguno de los padres. Asimismo, este estudio buscará potenciar la labor de los padres y/o tutores como co-terapeutas en los centros de educación especial, dándole fundamental énfasis en el rol del progenitor como elemento activo del tratamiento del niño. De este modo, el padre, madre o ambos podrán tener mayor información sobre las conductas típicas en relación a la edad de su hijo, identificar lugares que podrían disparar alguna reacción conflictiva en el menor y potenciar las habilidades que disminuyen los eventos desadaptativos(Bautista, Sifuentes, Jiménez, Avelar, \& Miranda, 2006).

En cuanto a las limitaciones encontradas en la investigación fueron en primer lugar, delimitar el tamaño de la muestra exacta. Esto no fue posible pues no existen estadísticas de personas con autismo en el país que ayuden a tener dicha proporción. Otro punto importante es que algunos padres rechazaban ser parte de la investigación por diferentes motivos, como incomodidad o falta de tiempo para realizar ambos cuestionarios. Además, resaltó la heterogeneidad de la muestra, pues la cantidad de mujeres que participaron fue mucho mayor que la de los hombres.

Por otro lado, la confiabilidad de las puntuaciones obtenidas en la prueba LOT-R no fue alta, esto sería un punto cuestionable en el estudio. Puede deberse a la limitada muestra a la que se tuvo acceso, las características particulares que debían cumplir dichos participantes y los pocos ítems de la prueba que pretenden medir el concepto global de optimismo.

Según los resultados obtenidos se sugiere que se validen las escalas en una población con características similares para obtener mayor confianza en los datos arrojados. Asimismo, sería oportuno realizar un estudio más completo, complementarlo con un análisis cualitativo respondería a muchas otras preguntas relacionadas a las dos variables, ya que ampliaría los relatos de las vivencias personales de cada uno de los padres y explicaría ciertos factores por los que se llegó a tal nivel de optimismo y tipo de afrontamiento.

En cuestión de las aplicaciones, se recomienda realizarlas también con personas del interior del país, con el fin de establecer las diferencias entre padres y madres que residen en la capital con los que se encuentran en provincias. Tal como se analizó en un estudio en Colombia(Londoño, Hernandez, Alejo, \& Pulido, 2013), en el que sí se verificó que las personas que residían en la capital presentaban un mayor grado de optimismo que aquellas que vivían en provincia. Con esto se podría saber si existen ciertas características o rasgos en las personas dentro de una misma comunidad que los lleva a 
enfrentar situaciones de manera similar en relación a otro lugar de residencia, ya sea por mejor acceso a la información, tecnología, salud u otras variables.

Por último, se sugiere incluir nuevas variables al estudio, para ampliar el panorama que involucra las experiencias que se viven incluyendo esta condición. Por ejemplo, la variable Resiliencia de los padres podría dar nuevas luces a la capacidad para haber superado obstáculos en el transcurso de su vida y la mirada que dan ahora a la condición y desarrollo de su hijo. Además, podrían interesar los resultados con la variable Adaptación, pues algunas personas tienen mayor facilidad para acomodarse a diferentes situaciones, mientras que otros necesitan de más tiempo y de ambientes sostenedores para asimilarlo con éxito (Pozo M. , 2010). Sería interesante estudiar estas variables en investigaciones longitudinales, para observar cómo el paso del tiempo repercute en los resultados.

Es indiscutible que el Autismo está siendo tomado en cuenta con mayor profundidad por parte de la población, esto ha generado movimientos en las medidas que se adoptan para que sea un tema de relevancia en todos los ámbitos: escolares, sociales, gubernamentales, etc. Por ello, esta investigación busca aportar con variables positivas la labor de ser padres, a fin de presenciar resultados tangibles y tomar acciones pertinentes para impulsar una mejor calidad de vida en los progenitores y la percepción global que se tiene de ellos. 


\section{BIBLIOGRAFÍA}

(s.f.).

Albarracin, A., Rey, L., \& Jaimes, M. (2014). Estrategias de Afrontamiento y características sociodemográficas en padres de hijos con trastornos del espectro autista. Revista Virtual Universidad Católica del Norte.

Aldás, J. (2005). Análisis de datos avanzados. Análisis Factorial. Obtenido de http://www.uv.es/aldas/resources/Docencia/UNR/FACTORIALEXPLORATORIO.pdf

Álvarez, R., \& Joancely, J. (2014). Relación entre los niveles de carga, la salud física autopercibida y los niveles de depresión en las cuidadoras principales de niños y jóvenes con autismo (Tesis de pregrado). Barquisimeto, Venezuela.

Ayuda, R., Llorente, M., Martos, J., Rodríguez, L., \& Olmo, L. (2012). Medidas de estrés e impacto familiar en padres de niños con trastornos del espectro autista antes y después de su participación en un programa de formación. Revista de Neurología,, 73-80.

Baio, J. (2012). Prevalence of AutismSpectrumDisorders - Autism and DevelopmentalDisabilitiesMonitoringNetwork. Morbidity and Mortality Weekly Report.

Barker, E., Hartley, S., Seltzer, M., Floyd, F., Greenberg, J., \& Orsmond, G. (2011). Trajectories of emotional well-being in mothersof adolescents and adults with Autism. Developmental Psychology.

Basa, A. (2010). Estrés parental con hijos autistas. Un estudio comparativo (Tesis de pregrado). Pontificia Universidad Católica de Argentina. Buenos Aires,Argentina.

Bautista, E., Sifuentes, N., Jiménez, B., Avelar, E., \& Miranda, A. (2006). Padres de Familia y su inclusión en la evaluación y tratamiento conductual del autismo. Revista Intercontinental de Psicología y Educación, 49-62.

Benites, L. (2010). Autismo, Familia y Calidad de Vida. Revista de la Asociación de Docentes de la USMP, 24,1-20.

Campbell, O., \& Figueroa, A. (2000). El autismo en la familia. La percepción de los padres. Archivos de Investigación Pediátrica de México,.

Cano, F., Sanduvete, S., Chacón, S., Rodríguez, L., Garcia, J., Antuña, M., y otros. (2015). Estructura factorial de la versión española del Test de Orientación Vital 
Revisado (LOT-R): comprobación de varios modelos. International Journal of Clinical and Health Psychology.

Casado, F. (2002). Modelo de Afrontamiento de Lazarus como heurístico de las intervenciones psicoterapéuticas.

Cassaretto, M., Chau, C., Oblitas, H., \& Valdez, N. (2003). Estrés y afrontamiento en estudiantes de Psicología. Revista de Psicología de la PUCP, 363-392.

Castaño, M., \& León, B. (2010). Estrategias de afrontamiento del estrés y estilos de conducta interpersonal. International Journal of Psychology and Psychological Therapy,.

Chico, E. (2002). Optimismo Disposicional como Predictor de Estrategias de Afrontamiento, Psicothema,

Costello, A., \& Osborne, J. (2005). Best practices in exploratory factor analysis: four recommendations for getting the most from your analysis.

Dabrowska, A., \& Pisula, E. (2010). Parenting Stress and Coping Styles in mothers and fathers of pre - school children with autism and Downsyndrome.

Del Cid, T. (2016). Rasgos depresivos y estrategias de afrontamiento en cuidadores de personas con autismo (Tesis de pregrado). Madrid, España.

Epstein, T., Saltzman Benaiah, J., O'Hare, A., Goll, J., \& Truck, S. (2008). Associated features of Asperger Syndrome and their relationship to parenting stress. Child: Health, Care and Development.

Field, A. (2009). Discovering Statistics Using SPSS (and sex and drugs and rock 'n' roll).Obtenido de http://www.soc.univ.kiev.ua/sites/default/files/library/elopen/andy-fielddiscovering-statistics-using-spss-third-edition-20091.pdf

Flores Lozano, J. (2006). Optimismo y Salud. The Gerontologist.

Frazier, L. (2000). Coping with disease-related stressors in Parkinson's disease.

Gantiva, A., Luna, A., Dávila, A., \& Salgado, M. (2010). Estrategias de afrontamiento en personas con ansiedad. Psychologia. Avances de la disciplina,.

Garcia, A., \& Diaz, J. (2010). Relación entre Optimismo/Pesimismo Disposicional, Rendimiento y Edad en jugadores de fútbol de competición. Revista de Iberoamericana de Psicología del Ejercicio y el Deporte, 45-60.

Garcia, L., \& Pérez, M. (2016). Trastorno del espectro del autismo y familia: revisión teórica sobre intervenciones basadas en la Psicología Positiva y la Terapia Narrativa (Tesis de pregrado). 
George, D., \& Mallery, P. (2003). PSS for Windows step by step: A Simple Guide and Reference. Obtenido de http://wps.ablongman.com/wps/media/objects/385/394732/george4answers.pdf

Giles, E. (2007). Guía para la Atención Educativa del Alumnado con Trastorno Generalizado del Desarrollo (Autismo). http://recursos.educarex.es/pdf/recursosdiversidad-DGCEE/Guia_Autismo.pdf.

Giné, C., Balcells, A., Simó, D., \& Font Roura, J. (2011). Necesidades de apoyo de las familias depersonas con discapacidad intelectual de Cataluya. Revista Española sobre Discapacidad Intelectual,.

Gómez, \& Porras. (2010). Relación de las Estrategias de Afrontamiento con los Niveles de Depresión en las Adolescentes Escolarizadas (Tesis de maestría).

Gray, D. (2006). Coping over time: the parents of children with autism. Journal of Intellectual Disability Research,.

Grimaldo, M. (2004). Niveles de Optimismo en un Grupo de Estudiantes de una Universidad Particular de la Ciudad de Lima.Liberabit,.

Hastings, R., \& Johnson, E. (2001). Stress in UK families conducting intensive homebased behavioral intervention for their young child with autism. Journal of Autism and Developmental Disorders.

Hastings, R., Kovshoff, H., Brown, T., Ward, N., Espinosa, F., \& Remington, B. (2005). Coping strategies in mothers and fathers of preschool and school-age children with autism. Autism.

Hernández, R., Fernández, C., \& Baptista, P. (2010). Metodología de la Investigación. Quinta edición.

Herrera, C., \& Cuervo, A. (2017). Ser madre de un niño autista: Una aproximación comprensiva a la experiencia de maternidad de una madre en torno al autismo. (Tesis de pregrado),.

Hunter, C. (2013). vida adulta y envejecimiento. Autismo Diario. Obtenido de https://autismodiario.org/2013/07/04/autismo-vida-adulta-y-envejecimiento/

Jiménez, E. (2016). Resiliencia en padres y madres de niños con trastornos del espectro autista (Tesis de doctorado).

Khanna, R., Suresh, S., Smith, M., Patrick, J., Tworek, C., \& Becker-Cottrill, B. (2010). Assessment of Health - Related Quality of Life Among Primary Caregivers of Children with Autism Spectrum Disorders. Journal of Autism and Developmental Disorders, 1214-1227. 
Krsemien, D., Monchietti, A., \& Urquijo, S. (2005). Afrontamiento activo y adaptación al envejecimiento en mujeres de la ciudad de Mar de Plata: una revisión de la estrategia de autodistracción.

Landero, R., \& Gonzáles, M. (2009). Propiedades psicométricas de la versión española del Test de Optimismo Revisado (LOT-R) en una muestra de personas con fibromialgia. Ansiedad y Estrés.

Lecavalier, L., Leone, S., \& Wiltz, J. (2006). The impact of behaviour problems on caregiver stress in young people with Autism Spectrum Disorders. Journal of Intellectual Disability Research.

Ledesma, R., Macbeth, G., \& Cortada, N. (2008). Tamaño del efecto: Revisión teórica y aplicaciones con el sistema ViSta. Revista Latinoamericana de Psicología, 425439.

Londoño, C., Hernandez , L., Alejo, I., \& Pulido, D. (2013). Diseño y validación de la Escala de Optimismo Disposicional/Pesimismo-EOP. Universitas Psychologica.

Londoño, N., Henao, G., Puerta, I., Posada, S., Arango, D., \& Aguirre Acevedo, D. (2006). Propiedades Psicométricas y Validación de la Escala de Estrategias de Coping Modificada (EEC - M) en una muestra colombiana.

Lyons, A., Leon, S., Roecker, Phelps, C., \& Dunleavy, A. (2010). The Impact of Child Symptom Severity on Stress among Parents with ASD: The moderating Role of Coping Styles.

Marcelli, D., \& De Ajuriaguerra, J. (2006). Psicopatología del niño. https://books.google.com.pe/books? $\mathrm{id}=\mathrm{oXvqRxgzsqUC \& printsec}=$ frontcover\&h $\mathrm{l}=\mathrm{es} \&$ source $=\mathrm{gbs} \_\mathrm{ge}$ _summary_r\&cad $=0 \# \mathrm{v}=$ onepage $\& \mathrm{q} \& \mathrm{f}=\mathrm{false}$.

Marrero, R., \& Carballera, M. (2010). El papel del optimismo y del apoyo social en el bienestar subjetivo. Salud menta.

Martínez, A., Reyes del Paso, G., García, A., \& González, M. (2006). Optimismo/Pesimismo disposicional y estrategias de afrontamiento del estrés, Psicothema.

Martínez, M. y Bilbao, M. (2008). Acercamiento a la realidad de las familias de personas con autismo. Psychosocial Intervention, 215-230.

Maseda, P. (2015). Estudio del funcionamiento de familias que tienen hijos/as con trastorno del espectro del autismo desde una perspectiva parental(Tesis doctoral). 
Medina, M. (2017). Afrontamiento y Optimismo Disposicional en pacientes mujeres con cáncer de mama.

Mendoza, X. (2014). Estrés parental y optimismo en padres de niños con trastorno del espectro autista. Pontificia Universidad Católica del Perú, Tesis de pregrado, Lima - Perú.

Mera, P., \& Ortiz, M. (2012). La Relación del Optimismo y las Estrategias de Afrontamiento con la Calidad de Vida de Mujeres Con Cáncer de Mama, Terapia psicológica, .

Monat, A., Lazarus, R., \& Reevy, G. (2007). The Praeger Handbook on Stress and Coping.London, Reino Unido: Praeger.

Montoya, O. (2007). Aplicación del Análisis Factorial a la Investigación de Mercados. Caso de Estudio. Scientia et Technica,.

Morales, A., Arenas, M., Reig-Ferrer, A., Álvarez-Ude, F., Malek, T., Moledous, A., y otros. (2011). Optimismo Disposicional en pacientes en hemodiálisis y su influencia en el curso de la enfermedad. Nefrología, 199-205.

Morales, N. (2013). La experiencia del cuidador, un acercamiento al autismo basado en los relatos familiares. Obtenido de http://ridum.umanizales.edu.co:8080/xmlui/bitstream/handle/6789/788/Morales Orozco_Nataly_2013.pdf?sequence=1

Navarro, M. (2008). Manejo de conflictos y emociones en los padres. Estrés. [Mensaje en un blog]. Hasta la luna ida y vuel...TA. Obtenido de http://hastalalunaidayvuelta.blogspot.pe/2008/10/manejo-de-conflictos-yemociones-en-los.html

Nieto. (2012). Estrategias de Afrontamiento ante el riesgo de recaída en adolescentes que realizaron tratamiento de recuperación para el trastorno por consumo de sustancias psicoactivas.

Oliden, S. (2013). Propiedades Psicométricas del Test de Orientación Vital Revisado (LOT - R) en un grupo de universitarios de Lima Metropolitana.

OMS. (2016). Trastornos del espectro autista. Organización Mundial de la Salud.

Pineda, D. (2012). Estrés parental y estilos de afrontamiento en padres de niños con trastornos del espectro autista (Tesis de pregrado). Lima, Perú.

Pozo, M. (2010). Adaptación psicológica en madres y padres de personas con trastornos del espectro autista: un estudio multidimensional (Tesis doctoral). 
Pozo, P., \& Sarriá, E. (2015). Coping Strategies and Parents' Positive Perceptions of Raising a Child with Autism Spectrum Disorders.Autism Spectrum Disorder. Obtenido de http://dx.doi.org/10.5772/58966

Pozo, P., Sarria, E., \& Méndez, L. (2006). Estrés en madres de personas con trastornos del espectro autista. Psicothema.

Ramírez, M. (2005). Padres y Desarrollo de los Hijos: Prácticas de Crianza. Estudios Pedagógicos (Valdivia), 31(2)167-177.

Ramírez, O., \& Mogollón, D. (2013). El estrés de crianza en madres de hijos con la condición de autismo severo (CAS). Revista Multidisciplinaria Dialógica, 66-93.

Remor, E., Amorós, M., \& Carrobles, J. (2006). El optimismo y la experiencia de ira en relación con el malestar físico. Anales de Psicología, 37-44.

Rey, L., \& Jaimes, M. (2013). Estudio correlacional entre estrategias de afrontamiento y características sociodemográficas en padres de hijos con diagnóstico de Trastorno del Espectro Autista (TEA).(.

Rubia, M. (2011). Estilos y estrategias de afrontamiento en madres de niños con trastorno autista (Tesis de pregrado). Argentina.

Ruiz, N., Antón, P., González, E., \& Moya, L. (2012). Consecuencias del cuidado de personas con trastorno del espectro autista sobre la salud de sus cuidadores: estado actual de la cuestión. Revista Electrónica de Psicología Iztacala, 1571-1590.

Salgado, A. (2009). Felicidad, resiliencia y optimismo en estudiantes de colegios nacionales de la ciudad de Lima. Liberabit,.

Sánchez, A., \& Velasquez, A. (2014). Proceso de Ajuste Emocional de Padres cuyos Hijos presentan algún tipo de Discapacidad. Revista Electrónica Medicina, Salud y Sociedad, 34-47.

Seguí, J., Ortiz Tallo, M., \& Diego, Y. (2008). Factores asociados al estrés del cuidador primario de niños con autismo: Sobrecarga, psicopatología y estado de salud. Anales de Psicología.

Seligman, M. (2003). La auténtica felicidad. Barcelona: Vergara.

Sheier, M., Carver, C., \& Bridges, M. (1994). Distinguishing optimism from neuroticism (and trait anxiety, self-mastery, and self-esteem): A re-evaluation of the Life Orientation Test, Journal of Personality and Social Psychology,.

Suriá, R. (2014). Análisis del empoderamiento en padres y madres de hijos con discapacidad. Boletín de Psicología. 
Urzúa, A., \& Jame, A. (2008). Calidad de vida y estilos de afrontamiento en personas con patologías crónicas.

Velasco, M., Londoño, C., \& Alejo, I. (2014). Validación del cuestionario de optimismo disposicional usando la teoría de respuesta al ítem. Perspectivas Psicológicas,.

Vera-Villarroel, P., \& Guerrero, A. (2014). Diferencias en habilidades de resolución de problemas sociales en sujetos optimistas y pesimistas. Universitas Psychologica.

Williams, B., Brown, T., \& Onsman, A. (2010). Exploratory factor analysis: A five-step guide for novices. Australasian Journal of Paramedicine,. 


\section{ANEXOS}

\section{Anexo 1. Consentimiento informado}

Yo,

\begin{tabular}{|c|c|}
\hline No Acepto & Acepto \\
\hline$(\quad)$ & $(\quad)$ \\
\hline
\end{tabular}

Demanera voluntaria colaborar con el proyecto de tesis sobre "Optimismo y Afrontamiento en padres de niños con autismo", realizado por la alumna KatitzaMiskulinGilardi del XII ciclo de la carrera de Psicología de la Universidad Peruana de Ciencias Aplicadas (UPC). La información obtenida será con fines exclusivamente académicos, manteniendo siempre el anonimato de los participantes, durante y posterior a la investigación.

Los dos cuestionarios que se realizarán serán: el Cuestionario de Orientación Vital Revisado (LOT - R) y la Escala de Estrategias de Afrontamiento Modificada (EEM - C), tomando entre 30 a 35 minutos finalizarlos.

Dado que la participación en los cuestionarios es voluntaria, es posible decidir retirarme del proceso en caso experimente incomodidad durante la realización de estos.

El objetivo de esta investigación es determinar de qué manera el grado de optimismo se relaciona y con las estrategias de afrontamiento que los padres tienen, de acuerdo ala realidad de educar y criar a un hijo con autismo.

He sido informado(a) de las condiciones, por lo tanto acepto colaborar con el cuestionario realizado.

Lima, de del 201

Firma del participante:

DNI 


\section{Anexo 2. Ficha sociodemográfica (Padre/Madre)}

Sexo: Hombre Mujer

Edad:

Grado de Instrucción:

Primaria Universitario Secundaria Post - grado Técnico

Estado Civil:

Soltero

Casado/Conviviente

Viudo

Divorciado

Ocupación actual:

Número de hijos:

Edad del hijo con autismo:

Lugar que ocupa entre los hermanos (Ejm: 1/1):

Edad del niño al momento del diagnóstico:

Su hijo recibe terapia actualmente: Sí No

Si respondió "Sí", tomando la edad del niño como base, especifique en qué momento se acudió por primera vez a terapia:

De qué tipo:

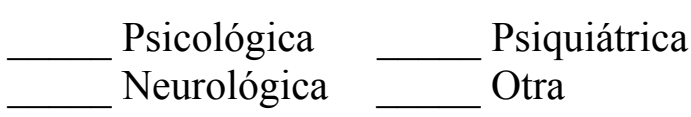

Frecuencia de citas:

Ha recibido antes otras terapias el niño: Sí No

De qué tipo:

Psicológica

Psiquiátrica

Neurológica

Otros:

Especifique:

Frecuencia de citas:

Como padre/madre recibe o ha recibido soporte o ayuda frente al diagnóstico de su hijo:

Actualmente

Aní $_{\text {Anteriormente }}$ No
Sí No

De qué tipo (puede marcar más de una): Psicológica Psiquiátrica Neurológica Otros:

Especifique:

Acude su hijo a un centro de educación especial: Sí No

¿Cuánto tiempo tiene su hijo acudiendo al mismo centro de educación especial?: años

Ha acudido a otro centro de educación antes: Sí No

Por cuánto tiempo: años 


\section{Anexo 3. Cuestionario 1: LOT-R}

Instrucciones: Las siguientes preguntas se refieren a como usted ve la vida en general. Después de cada pregunta, díganos, si usted está de acuerdo o en desacuerdo. No hay respuestas correctas o incorrectas, sólo nos interesa su opinión.

\begin{tabular}{|c|c|c|c|c|}
\hline Muy en desacuerdo & Algo en desacuerdo & Indiferente & Algo de acuerdo & Muy de acuerdo \\
\hline 1 & 2 & 3 & 4 & 5 \\
\hline
\end{tabular}

1. ___ Cuando no se sabe qué va a suceder, normalmente espero lo mejor

2. ___ Me resulta fácil relajarme

3. ___ Cuando algo malo puede ocurrirme, termina sucediéndome

4. ___ Siempre soy optimista sobre mi futuro

5. ___ Disfruto mucho con los amigos

6. ___ Para mí es importante mantenerme ocupado

7. ___ Casi nunca espero que las cosas vayan a ir como yo deseo

8. ___ No me enfado demasiado fácilmente

9. Pocas veces cuento con que vayan a sucederme cosas buenas

10. ___ En general, espero que me ocurran más cosas buenas que malas 


\section{Anexo 4. Cuestionario 2: EEC - M}

A continuación se plantean diferentes formas que emplean las personas para afrontar los problemas o situaciones estresantes que se les presentan en la vida. Las formas de afrontamiento aquí descritas no son ni buenas ni malas, ni mejores o peores. Simplemente ciertas personas utilizan unas formas más que otras, dependiendo de la situación problema. Trate de recordar las diferentes situaciones o problemas más estresantes vividos durante los últimos años, y responda

señalando con una $\mathrm{X}$ en la columna que le señale el número que mejor indique qué tan habitual ha sido esta forma de comportamiento ante las situaciones estresantes.

\begin{tabular}{|c|c|c|c|c|c|}
\hline 1 & 2 & 3 & 4 & 5 & 6 \\
\hline Nunca & Casi nunca & A veces & Frecuentemente & $\begin{array}{c}\text { Casi } \\
\text { siempre }\end{array}$ & Siempre \\
\hline
\end{tabular}

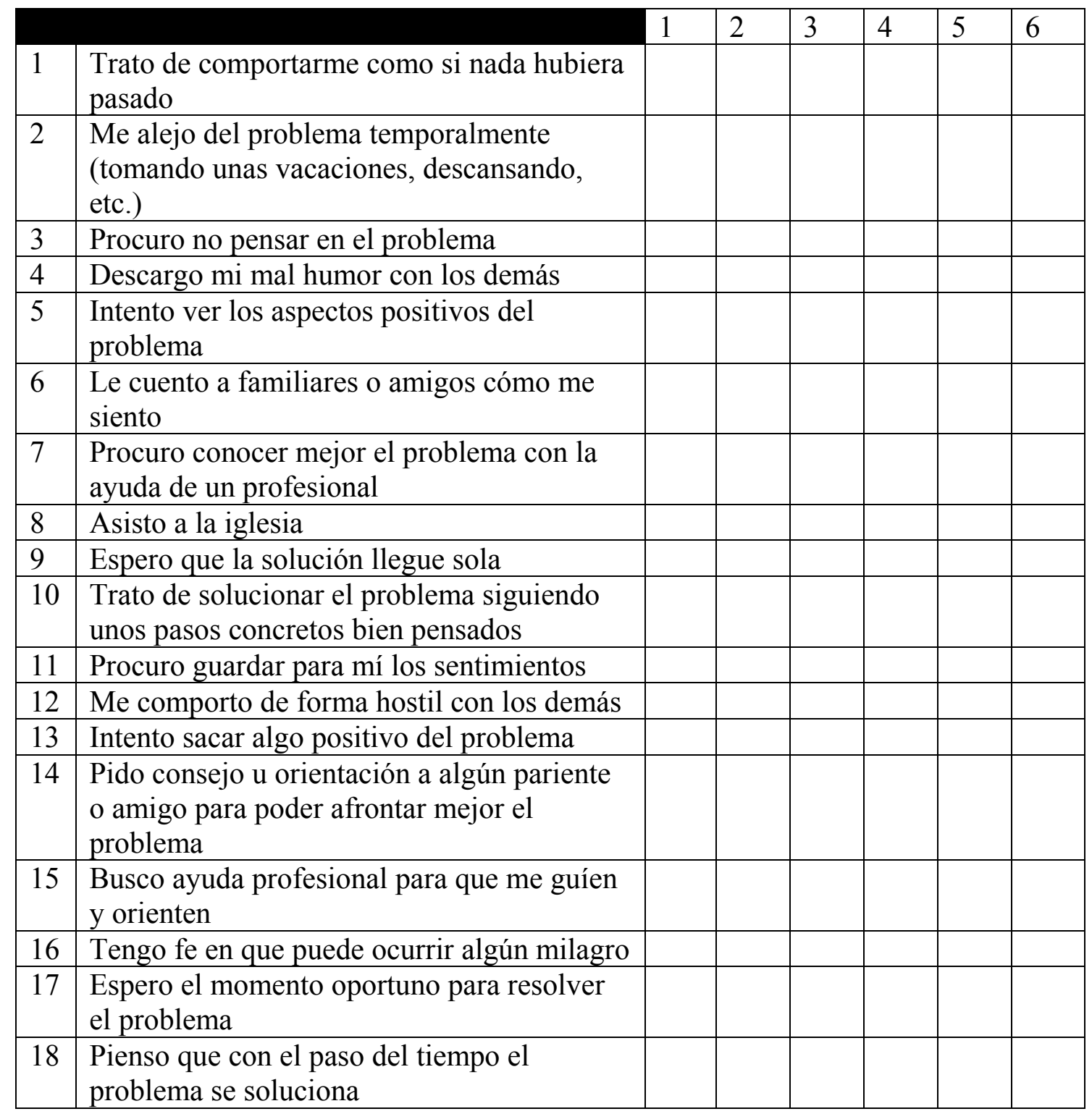




\begin{tabular}{|c|l|l|l|l|l|l|l|}
\hline 19 & $\begin{array}{l}\text { Establezco un plan de actuación y procuro } \\
\text { llevarlo a cabo }\end{array}$ & & & & & & \\
\hline 20 & $\begin{array}{l}\text { Procuro que los otros no se den cuenta de lo } \\
\text { que siento }\end{array}$ & & & & & & \\
\hline 21 & $\begin{array}{l}\text { Evado las conversaciones o temas tienen } \\
\text { que ver con el problema }\end{array}$ & & & & & \\
\hline
\end{tabular}

\begin{tabular}{|l|l|l|l|l|l|}
\hline 1 & 2 & 3 & 4 & 5 & 6 \\
\hline Nunca & Casi nunca & A veces & Frecuentemente & $\begin{array}{l}\text { Casi } \\
\text { siempre }\end{array}$ & Siempre \\
\hline
\end{tabular}

\begin{tabular}{|c|c|c|c|c|c|c|c|}
\hline & & 1 & 2 & 3 & 4 & 5 & 6 \\
\hline 22 & $\begin{array}{l}\text { Expreso mi rabia sin calcular las } \\
\text { consecuencias }\end{array}$ & & & & & & \\
\hline 23 & $\begin{array}{l}\text { Pido a parientes o amigos que me ayuden a } \\
\text { pensar acerca del problema }\end{array}$ & & & & & & \\
\hline 24 & $\begin{array}{l}\text { Procuro hablar con personas responsables } \\
\text { para encontrar una solución al problema }\end{array}$ & & & & & & \\
\hline 25 & Tengo fe en que Dios remedie la situación & & & & & & \\
\hline 26 & $\begin{array}{l}\text { Pienso que hay un momento oportuno para } \\
\text { analizar la situación }\end{array}$ & & & & & & \\
\hline 27 & No hago nada porque el tiempo todo lo dice & & & & & & \\
\hline 28 & $\begin{array}{l}\text { Hago frente al problema poniendo en } \\
\text { marcha varias soluciones }\end{array}$ & & & & & & \\
\hline 29 & Dejo que las cosas sigan su curso & & & & & & \\
\hline 30 & Trato de ocultar mi malestar & & & & & & \\
\hline 31 & $\begin{array}{l}\text { Salgo al cine, a dar una vuelta, etc., para } \\
\text { olvidarme del problema }\end{array}$ & & & & & & \\
\hline 32 & Evito pensar en el problema & & & & & & \\
\hline 33 & Me dejo llevar por mi mal humor & & & & & & \\
\hline 34 & $\begin{array}{l}\text { Hablo con amigos o familiares para que me } \\
\text { animen o tranquilicen cuando me encuentro } \\
\text { mal }\end{array}$ & & & & & & \\
\hline 35 & $\begin{array}{l}\text { Busco la ayuda de algún profesional para } \\
\text { reducir mi ansiedad o malestar }\end{array}$ & & & & & & \\
\hline 36 & Rezo & & & & & & \\
\hline 37 & $\begin{array}{l}\text { Hasta que no tenga claridad frente a la } \\
\text { situación, no puedo darle la mejor solución a } \\
\text { los problemas }\end{array}$ & & & & & & \\
\hline 38 & $\begin{array}{l}\text { Pienso que lo mejor es esperar a ver qué } \\
\text { puede pasar }\end{array}$ & & & & & & \\
\hline 39 & $\begin{array}{l}\text { Pienso detenidamente los pasos a seguir } \\
\text { para enfrentarme al problema }\end{array}$ & & & & & & \\
\hline 40 & Me resigno y dejo que las cosas pasen & & & & & & \\
\hline 41 & Inhibo mis propias emociones & & & & & & \\
\hline
\end{tabular}




\begin{tabular}{|l|l|l|l|l|l|l|l|}
\hline 42 & Busco actividades que me distraigan & & & & & & \\
\hline 43 & Niego que tengo problemas & & & & & & \\
\hline 44 & Me salgo de casillas & & & & & & \\
\hline 45 & $\begin{array}{l}\text { Por más que quiera no soy capaz de expresar } \\
\text { abiertamente lo que siento }\end{array}$ & & & & & & \\
\hline 46 & $\begin{array}{l}\text { A pesar de la magnitud de la situación } \\
\text { tiendo a sacar algo positivo }\end{array}$ & & & & & & \\
\hline 47 & $\begin{array}{l}\text { Pido a algún amigo o familiar que me } \\
\text { indique cuál sería el mejor camino a seguir }\end{array}$ & & & & & & \\
\hline
\end{tabular}

\begin{tabular}{|c|c|c|c|c|c|}
\hline 1 & 2 & 3 & 4 & 5 & 6 \\
\hline Nunca & Casi nunca & A veces & Frecuentemente & $\begin{array}{c}\text { Casi } \\
\text { siempre }\end{array}$ & Siempre \\
\hline
\end{tabular}

\begin{tabular}{|c|l|l|l|l|l|l|l|}
\hline 48 & $\begin{array}{l}\text { Pido ayuda a algún médico o psicólogo para } \\
\text { aliviar mi tensión }\end{array}$ & & & & & & \\
\hline 49 & Acudo a la iglesia para poner velas o rezar & & & & & & \\
\hline 50 & $\begin{array}{l}\text { Considero que las cosas por sí solas se } \\
\text { solucionan }\end{array}$ & & & & & \\
\hline 51 & $\begin{array}{l}\text { Analizo lo positivo y negativo de las } \\
\text { diferentes alternativas }\end{array}$ & & & & & & \\
\hline 52 & Me es difícil relajarme & & & & & & \\
\hline 53 & $\begin{array}{l}\text { Hago todo lo posible para ocultar mis } \\
\text { sentimientos a los otros }\end{array}$ & & & & & & \\
\hline 54 & $\begin{array}{l}\text { Me ocupo de muchas actividades para no } \\
\text { pensar en el problema }\end{array}$ & & & & & & \\
\hline 55 & Así lo quiera, no soy capaz de llorar & & & & & & \\
\hline 56 & $\begin{array}{l}\text { Tengo muy presente el dicho “al mal tiempo } \\
\text { buena cara" }\end{array}$ & & & & & & \\
\hline 57 & $\begin{array}{l}\text { Procuro que algún familiar o amigo me } \\
\text { escuche cuando necesito manifestar mis } \\
\text { sentimientos }\end{array}$ & & & & & & \\
\hline 58 & $\begin{array}{l}\text { Intento conseguir más información sobre el } \\
\text { problema acudiendo a profesionales }\end{array}$ & & & & & & \\
\hline 59 & Dejo todo en manos de Dios & & & & & & \\
\hline 60 & Espero que las cosas se vayan dando & & & & & & \\
\hline 61 & $\begin{array}{l}\text { Me es difícil pensar en posibles soluciones a } \\
\text { mis problemas }\end{array}$ & & & & & & \\
\hline 62 & Trato de evitar mis emociones & & & \\
\hline 63 & $\begin{array}{l}\text { Dejo a un lado los problemas y pienso en } \\
\text { otras cosas } \\
\text { problema identificar las ventajas del }\end{array}$ & & & & & & \\
\hline 64 & \begin{tabular}{lll} 
Trato de \\
\hline
\end{tabular} & & & & & & \\
\hline
\end{tabular}




\begin{tabular}{|l|l|l|l|l|l|l|l|}
\hline 65 & $\begin{array}{l}\text { Considero que mis problemas los puedo } \\
\text { solucionar sin la ayuda de los demás }\end{array}$ & & & & & & \\
\hline 66 & $\begin{array}{l}\text { Pienso que no necesito la ayuda de nadie y } \\
\text { menos de un profesional }\end{array}$ & & & & & & \\
\hline 67 & Busco tranquilizarme a través de la oración & & & & & & \\
\hline 68 & $\begin{array}{l}\text { Frente a un problema, espero conocer bien } \\
\text { la situación antes de actuar }\end{array}$ & & & & & & \\
\hline 69 & Dejo que pase el tiempo & & & & & & \\
\hline
\end{tabular}




\section{Anexo 5. Nueva estructura utilizada de la Prueba EEC-M}

\begin{tabular}{|c|c|c|c|c|c|}
\hline 1 & 2 & 3 & 4 & 5 & 6 \\
\hline Nunca & Casi nunca & A veces & Frecuentemente & $\begin{array}{c}\text { Casi } \\
\text { siempre }\end{array}$ & Siempre \\
\hline
\end{tabular}

\begin{tabular}{|c|c|c|c|c|c|c|c|}
\hline & & 1 & 2 & 3 & 4 & 5 & 6 \\
\hline 1 & $\begin{array}{l}\text { Intento ver los aspectos positivos del } \\
\text { problema }\end{array}$ & & & & & & \\
\hline 2 & Procuro guardar para mí los sentimientos & & & & & & \\
\hline 3 & Intento sacar algo positivo del problema & & & & & & \\
\hline 4 & $\begin{array}{l}\text { Espero el momento oportuno para resolver } \\
\text { el problema }\end{array}$ & & & & & & \\
\hline 5 & $\begin{array}{l}\text { Establezco un plan de actuación y procuro } \\
\text { llevarlo a cabo }\end{array}$ & & & & & & \\
\hline 6 & $\begin{array}{l}\text { Procuro que los otros no se den cuenta de lo } \\
\text { que siento }\end{array}$ & & & & & & \\
\hline 7 & $\begin{array}{l}\text { Evado las conversaciones o temas tienen } \\
\text { que ver con el problema }\end{array}$ & & & & & & \\
\hline 8 & $\begin{array}{l}\text { Pienso que hay un momento oportuno para } \\
\text { analizar la situación }\end{array}$ & & & & & & \\
\hline 9 & $\begin{array}{l}\text { Hago frente al problema poniendo en } \\
\text { marcha varias soluciones }\end{array}$ & & & & & & \\
\hline 10 & Trato de ocultar mi malestar & & & & & & \\
\hline 11 & $\begin{array}{l}\text { Pienso detenidamente los pasos a seguir } \\
\text { para enfrentarme al problema }\end{array}$ & & & & & & \\
\hline 12 & Inhibo mis propias emociones & & & & & & \\
\hline 13 & Niego que tengo problemas & & & & & & \\
\hline 14 & $\begin{array}{l}\text { A pesar de la magnitud de la situación } \\
\text { tiendo a sacar algo positivo }\end{array}$ & & & & & & \\
\hline 15 & $\begin{array}{l}\text { Analizo lo positivo y negativo de las } \\
\text { diferentes alternativas }\end{array}$ & & & & & & \\
\hline 16 & $\begin{array}{l}\text { Hago todo lo posible para ocultar mis } \\
\text { sentimientos a los otros }\end{array}$ & & & & & & \\
\hline 17 & $\begin{array}{l}\text { Tengo muy presente el dicho "al mal tiempo } \\
\text { buena cara" }\end{array}$ & & & & & & \\
\hline 18 & Trato de evitar mis emociones & & & & & & \\
\hline 19 & $\begin{array}{l}\text { Trato de identificar las ventajas del } \\
\text { problema }\end{array}$ & & & & & & \\
\hline 20 & $\begin{array}{l}\text { Frente a un problema, espero conocer bien } \\
\text { la situación antes de actuar }\end{array}$ & & & & & & \\
\hline
\end{tabular}

